\title{
Quantitative Evaluation for Reinforcement Effect of Auxiliary Steel Beams Based on Running Safety and Dynamic Response
}

\author{
Gong Kai $\mathbb{D}^{1},{ }^{1}$ Liu Linya $\mathbb{D}^{1},{ }^{1}$ Xiang Jun, ${ }^{2}$ Yang Haiming, ${ }^{2}$ and Yu Cuiying ${ }^{3}$ \\ ${ }^{1}$ Engineering Research Center of Railway Environmental Vibration and Noise Ministry of Education, \\ East China Jiaotong University, Nanchang 330013, China \\ ${ }^{2}$ School of Civil Engineering, Central South University, Changsha 410075, China \\ ${ }^{3}$ School of Science, East China Jiaotong University, Nanchang 330013, China \\ Correspondence should be addressed to Gong Kai; gongkai1986@126.com and Liu Linya; lly1949@163.com
}

Received 15 October 2020; Revised 15 March 2021; Accepted 8 April 2021; Published 2 June 2021

Academic Editor: Pedro A. Costa

Copyright (C) 2021 Gong Kai et al. This is an open access article distributed under the Creative Commons Attribution License, which permits unrestricted use, distribution, and reproduction in any medium, provided the original work is properly cited.

\begin{abstract}
Aiming at the existing heavy-haul railway, bridges hardly meet the transportation requirements. Based on the spatial vibration calculation model of the freight train-track-bridge (FTTB) system, the FTTB spatial vibration model under the condition of auxiliary steel beam reinforcement is established. Besides, according to the random analysis method of train derailment energy, coming up with an evaluation method of auxiliary steel beam reinforcement is based on safety and dynamic response, which is used to discuss the train safety and the change law of FTTB system vibration response. The results show that the derailment resistance of the FTTB system is increased by $22.6 \%$ after the auxiliary steel beam is reinforced. Compared with the previous speed $(115.56 \mathrm{~km} / \mathrm{h})$, the speed is $132.73 \mathrm{~km} / \mathrm{h}$ after the auxiliary steel beam reinforcement; at the same time, the allowable limit speed increases from $92.49 \mathrm{~km} / \mathrm{h}$ to $106.18 \mathrm{~km} / \mathrm{h}$. In addition, the reinforcement of the auxiliary steel beam can not only effectively reduce the lateral vibration response of the FTTB system under the action of empty wagon but also effectively decline the vertical vibration response of the FTTB system under the action of the loaded wagon, which can meet the stability requirement for running at the speed of $90 \mathrm{~km} / \mathrm{h}$. In summary, the reinforcement of auxiliary steel beams can improve the running safety of trains, reduce the vibration response of the FTTB system, and meet the requirements of operation stability.
\end{abstract}

\section{Introduction}

Bridges are one of the infrastructures of heavy-haul railways as well as an important guarantee for safety train operation. Simply supported concrete T-beam bridge is a common bridge type of heavy-haul railway in China [1]. With the increasing of train axle load and the number of formation cars and the increase of train speed and traffic density, the existing bridge is difficult to meet the urgent requirements of heavy-haul transportation, which is mainly manifested in the insufficient bearing capacity and stiffness of the beam body, resulting in excessive beam amplitude, serious vehicle shaking, and even train derailment accidents $[2,3]$.

Aiming at the traffic safety problems caused by the insufficient bearing capacity and stiffness of the existing bridge, domestic and aboard scholars have carried out a series of reinforcement research for the bridge structure and put forward corresponding reinforcement measures [2, 4-10]. For example, Puurula et al. [4] proposed to install carbon fiber materials on the bridge deck for a 50 -year concrete bridge in Sweden, and the influence of reinforcement measures on the bridge bearing capacity is analyzed. Robiul et al. [5] studied the influence of adding transverse support at the bottom of the double beam on the natural vibration characteristics and dynamic response of the beam. Abu-Obeidah et al. [6] proposed the strengthening measures of sticking aluminium alloy plates on the concrete beam bridge deck, and the variation law of the maximum deflection in the middle span of the beam is discussed when sticking aluminium alloy plates. Panda et al. [7] wrapped glass fiber reinforced polymer (GFRP) plate in reinforced concrete T-beam web, and the strain law of transverse and 
vertical reinforcement of beam is studied. Bousselham and Chaallal [8] used carbon fiber reinforced polymer (CFRP) composite materials to strengthen concrete beam and discussed the variation law of shear performance of beams. Zhai [2] studied the variation of natural vibration characteristics and vehicle-bridge dynamic response of ten typical speed-up railway concrete T-beam bridges after adding horizontal diaphragm under the condition of speed $200 \mathrm{~km} / \mathrm{h}$. Zhou [9] proposed using prestressed steel strands to implant diaphragms and laying longitudinal prestressed tendons of the bridge for the $32 \mathrm{~m}$ prestressed concrete T-beam bridge, and the changes of amplitude and acceleration of the bridge are analyzed. Han [10] studied the effects of thickening diaphragm and adding horizontal plate on the natural frequency of bridge and the mid-span transverse amplitude of beam body. In addition, auxiliary steel beam reinforcement as an external reinforcement measure of beam body has been applied to practical engineering in recent years because it has little damage to the original beam structure and does not affect the train operation. To evaluate the reinforcement effect of auxiliary steel beams, Jiang [11] studied the influence of the auxiliary steel beam reinforcement on the bridge natural vibration characteristics, beam mid-span amplitude and acceleration, and concluded that the auxiliary steel beam reinforcement can improve the bearing capacity and stiffness of the beam. Liu [12] used the $24 \mathrm{~m}$ ultralow-height concrete simply supported T-beam bridge on Shuohuang railway as the research object; the influence of auxiliary steel beam reinforcement on beam stress and vertical stiffness of the bridge is discussed. Zhang [13] and Cai [14] carried out experimental research on auxiliary steel beam reinforcement of ultra-low-height beam and analyzed the variation law of bearing capacity and stiffness of beam body. However, existing studies have explored the influence of auxiliary steel beam reinforcement on bridge vibration response, but there are few reports about the influence of auxiliary steel beam reinforcement on running safety and stability.

In this paper, based on the space vibration calculation model of freight train track bridge system (FTTB system) [15], according to the structural characteristics of auxiliary steel beam reinforcement, the spatial vibration calculation model of FTTB system under the condition of auxiliary steel beam reinforcement is established. According to the random energy analysis method of train derailment [16], the evaluation method about running safety and dynamic response of auxiliary steel beam reinforcement is proposed. The effect of running safety and dynamic response under the condition of auxiliary steel beam reinforcement are analyzed to provide reference for the development of auxiliary steel beam reinforcement measures to prevent train derailment and meet the requirements of operation stability.

\section{Spatial Vibration Model of FTTB System with Auxiliary Steel Beam Reinforcement Condition}

2.1. Spatial Vibration Calculation Model of FTTB System. FTTB system is an integrated system that contains freight train, track, and bridge. The connection condition of wheel
TABle 1: Vehicle unit displacement mode.

\begin{tabular}{lcccccc}
\hline Displacement mode & $X$ & $Y$ & $Z$ & Roll & Pitch & Yaw \\
\hline Car body & $\sqrt{ }$ & $\sqrt{ }$ & $\sqrt{ }$ & $\sqrt{ }$ & $\sqrt{ }$ & $\sqrt{ }$ \\
Front bogie & $\sqrt{ }$ & $\sqrt{ }$ & $\sqrt{ }$ & $\sqrt{ }$ & $\sqrt{ }$ & $\sqrt{ }$ \\
Rear bogie & $\sqrt{ }$ & $\sqrt{ }$ & $\sqrt{ }$ & $\sqrt{ }$ & $\sqrt{ }$ & $\sqrt{ }$ \\
Each wheelset & - & $\sqrt{ }$ & $\sqrt{ }$ & - & - & - \\
\hline
\end{tabular}

rail relative displacement [16] is taken as the link between train wheel and track, and the connection condition of wheel rail relative displacement is shown in the following formulae:

$$
\begin{aligned}
& \Delta Y_{\mathrm{wt}}=Y_{w}-Y_{t}-Y_{\text {ior }} \\
& \Delta Z_{\mathrm{wt}}=Z_{w}-Z_{t}-Z_{\text {ior }} .
\end{aligned}
$$

In formulae (1) and (2), $\Delta Y_{\mathrm{wt}}$ and $\Delta Z_{\mathrm{wt}}$ are relative lateral and vertical displacement of wheel/rail, respectively; $Y_{W}$ and $Z_{W}$ are lateral and vertical displacement of wheel, respectively; $Y_{t}$ and $Z_{t}$ are transverse and vertical displacement of rail, respectively; and $Y_{\text {ior }}$ and $Z_{\text {ior }}$ are transverse and vertical geometric irregularity of rail, respectively. At the same time, the influence of clearance between wheel flange and gauge line is considered.

There is a train running on the heavy-haul railway bridge which is composed of 1 locomotive $+M$ freight cars at a certain time. It is assumed that the locomotives and freight car are discrete into multibody vehicle units with 26 degrees of freedom. Each vehicle unit moves at a constant speed, and the car body and bogie are front and rear, left and right symmetry. The displacement mode of vehicle unit is shown in Table 1.

According to the above displacement mode, the spatial vibration potential energy $\Pi v i$ of the unit can be derived. The space vibration potential energy of train can be derived by superposing the potential energy of vehicle unit within the scope of train formation, as shown in formula (3). The derivation process is shown in the literature [16]. Consider

$$
\Pi_{V}=\sum_{i=1}^{1+M} \Pi_{\mathrm{Vi}}
$$

Simultaneously, along the beam span direction of heavyhaul railway, each adjacent diaphragm is divided into a beam segment element. In this way, the beam with effective length $L$ can be divided into $N$ beam segment elements. Each beam unit is composed of rail, fastener, sleeper, ballast, and T-beam. The rail, sleeper, and T-beam are simulated by beam element, and the fastener and ballast are simulated by linear spring and viscous damper. The lateral and vertical elastic coefficients are $K_{1}, K_{2}, K_{4}, K_{5}, K_{6}$, and $K_{7}$; the lateral and vertical damping coefficients are $C_{1}, C_{2}, C_{4}, C_{5}, C_{6}$, and $C_{7}$. Assuming that the displacement at the top of the pier is equal to that at the end of the girder, the pier is simulated by beam element and directly consolidated with the ground without considering the pile foundation effect. According to the number of piers and section characteristics, the pier is divided into 1 element. Thus, the 
spatial vibration calculation model of track bridge system is formed, as shown in Figure 1.

Based on the above assumption, each beam element is discretized into a finite element model with 50 degrees of freedom, and the node displacement of the element is shown in equation (4). The numbers 1 and 2 represent the left- and right-end node of beam element.

$$
\begin{aligned}
\{\delta\} & =\left\{\begin{array}{c}
\{\delta\}_{1} \\
\{\delta\}_{2}
\end{array}\right\}_{50 \times 1}, \\
\{\delta\}_{1} & =\left[U_{1 R}^{T}, V_{1 R}^{T}, W_{1 R}^{T}, \theta_{X 1 R}^{T}, \theta_{Y 1 R}^{T}, \theta_{Z 1 R}^{T}, \gamma_{1 R}^{T},\right. \\
& U_{1 L}^{T}, V_{1 L}^{T}, W_{1 L}^{T}, \theta_{X 1 L}^{T}, \theta_{Y 1 L}^{T}, \theta_{Z 1 L}^{T}, \gamma_{1 L}^{T}, \\
& V_{1}^{S}, V_{1 R}^{S}, W_{1 L}^{S}, \\
& \left.V_{1 U}^{B}, \theta_{Z 1 U}^{B}, V_{1 D}^{B}, \theta_{Z 1 D}^{B}, W_{1 R}^{B}, \theta_{Y 1 R}^{B}, W_{1 L}^{B}, \theta_{Y 1 L}^{B}\right], \\
\{\delta\}_{2} & =\left[U_{2 R}^{T}, V_{2 R}^{T}, W_{2 R}^{T}, \theta_{X 2 R}^{T}, \theta_{Y 2 R}^{T}, \theta_{Z 2 R}^{T}, \gamma_{2 R}^{T},\right. \\
& U_{2 L}^{T}, V_{2 L}^{T}, W_{2 L}^{T}, \theta_{X 2 L}^{T}, \theta_{Y 2 L}^{T}, \theta_{Z 2 L}^{T}, \gamma_{2 L}^{T}, \\
& V_{2}^{S}, V_{2 R}^{S}, W_{2 L}^{S}, \\
& \left.V_{2 U}^{B}, \theta_{Z 2 U}^{B}, V_{2 D}^{B}, \theta_{Z 2 D}^{B}, W_{2 R}^{B}, \theta_{Y 2 R}^{B}, W_{2 L}^{B}, \theta_{Y 2 L}^{B}\right] .
\end{aligned}
$$

In formulae (5) and (6), the superscripts $T, S$, and $B$ are, respectively, the displacements of rails, sleepers, and bridge girders; the subscripts $R$ and $L$ represent the right and left side of the beam segment element; $U, V, W$, and $\theta$ are the longitudinal, transverse, and vertical linear displacement and angular displacement along the bridge span direction, respectively; $\gamma$ is the change rate of the longitudinal torsional angle along the rail; the subscripts $U$ and $D$ represent the upper and lower flanges of the bridge girder, respectively, The subscripts $X, Y$, and $Z$ are the beam span direction (longitudinal), the horizontal direction perpendicular to the beam span (transverse), and the vertical direction perpendicular to the beam span (vertical).

According to the node displacement of the element in equation (4), the space vibration potential energy $\Pi_{T B j}$ of each beam segment element can be derived. Then, the space vibration potential energy $\Pi_{P}$ of each beam segment element can be superposed to obtain the space vibration potential energy $\Pi_{T B-P}$ of the track bridge system. The derivation process is shown in [15]

$$
\Pi_{T B-P}=\Pi_{T B}+\Pi_{P} .
$$

Furthermore, by superposing the abovementioned freight train spatial vibration potential energy and the track-bridge system spatial vibration potential energy, the total spatial vibration potential energy of the FTTB system can be obtained as shown in the following equation:

$$
\Pi_{\mathrm{FTTB}}=\Pi_{V}+\Pi_{T B-P} .
$$

According to the principle of constant value of the total potential energy of elastic system dynamics [17], equation (8) is changed and set to 0 , as shown in the following equation:

$$
\delta H_{\mathrm{FTTB}}=0 .
$$

Using the "set in right position" rule [18] that forms the system matrix equation, the spatial vibration matrix equation of the FTTB system at time $t$ is obtained as shown in the following equation:

$$
[K]\{\delta\}+[C]\{\dot{\delta}\}+[M]\{\ddot{\delta}\}=\{P\} .
$$

In formula $(10),[K],[C]$, and $[M]$ are stiffness, damping, and mass matrix of FTTB system, respectively; $\{P\}$ is the load array of FTTB system; and the load consists of lateral and vertical excitation sources of FTTB system, respectively, the bogie frame hunting wave, and track vertical geometric irregularity; and $\{\delta\},\{\delta\}$, and $\{\ddot{\delta}\}$ are the displacement, velocity, and acceleration arrays of the FTTB system. For equation (10), Wilson- $\theta$ step-by-step integration method is used to solve the equation, and FORTRAN programming language is used to program, to solve the space vibration response of FTTB system.

2.2. Simulation of Auxiliary Steel Beam Reinforcement. Auxiliary steel beam reinforcement is generally achieved in two ways [11]: one is the auxiliary steel beam and the transverse $T$-shaped connecting plate, and the T-shaped connecting plate and the concrete T-beam are connected by expansion bolts; the second is to drill holes at the bottom of the concrete T-beam and implanted connecting steel bars are implanted, and a section of concrete blocks are poured at regular intervals between the upper flange plate of the steel beam and the bottom of the concrete beam flange plate for connection. The structure diagram of auxiliary steel beam reinforcement is shown in Figure 2.

According to the characteristics of the auxiliary steel beam in Figure 2, it is assumed that the auxiliary steel beam and the original $T$-beam are taken as a whole, and the beam element is used to simulate. Meanwhile, the T-beam and the auxiliary steel beam maintain the assumption of flat section and meet the requirements of small deformation, and the micro slip caused by the shear connector is ignored. Using the equivalent section method [19], according to the unitaxial stress-strain relationship model of concrete and simplified stress-strain constitutive relationship of reinforcement and concrete, the section conversion is carried out based on the principle that the strength and bending stiffness of the components before and after deformation are equal. Within the effective width range, the section area of steel beam is equivalent to the section area of partial concrete, and the equivalent section can be regarded as a homogeneous elastic body.

The stress-strain relationship of structure is shown in the following equation:

$$
\left\{\begin{array}{l}
F=\sigma A \\
\sigma=E \mathcal{E}
\end{array} .\right.
$$

According to the principle of equivalent component strength, the equivalent calculation formula for component strength can be derived as shown in the following equation: 


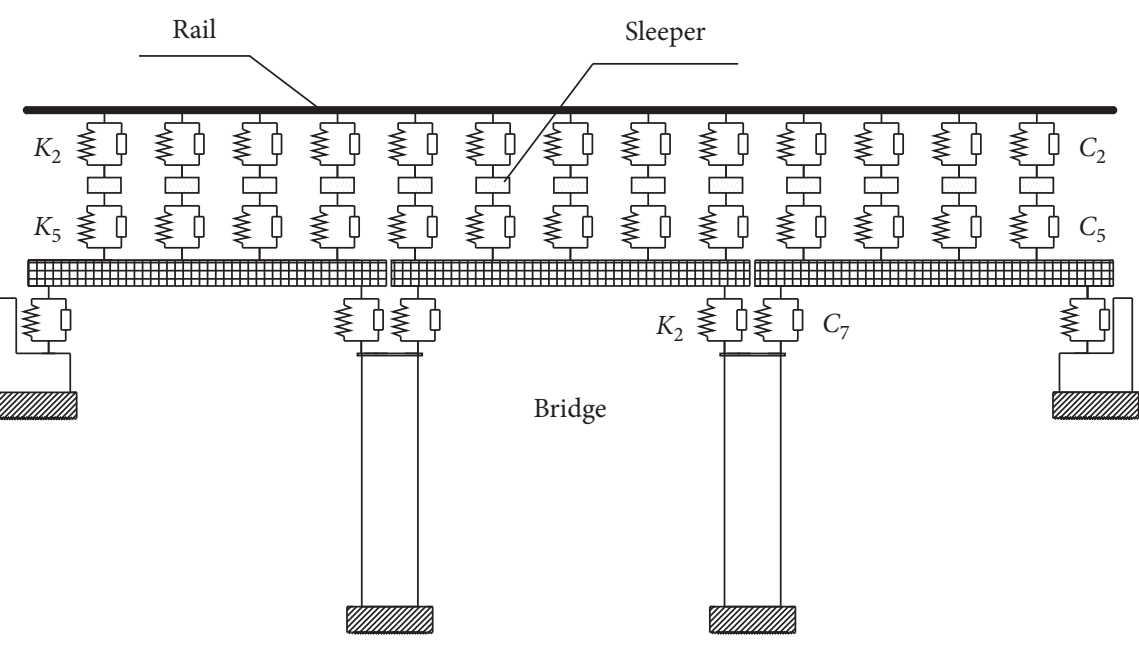

(a)

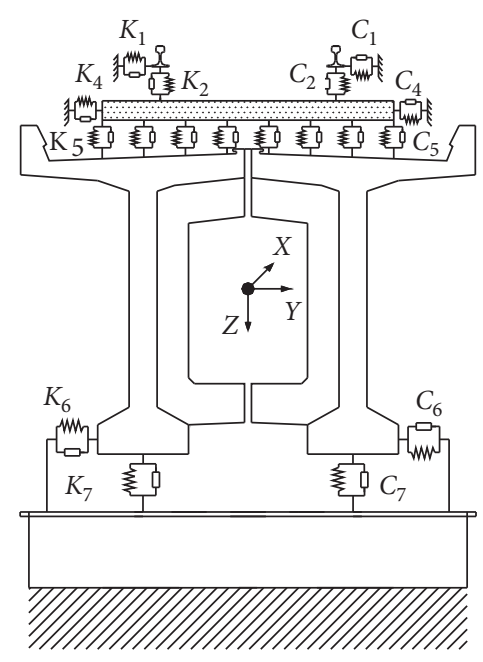

(b)

FIGURE 1: Spatial vibration model of track and bridge system. (a) Main view. (b) Side view.

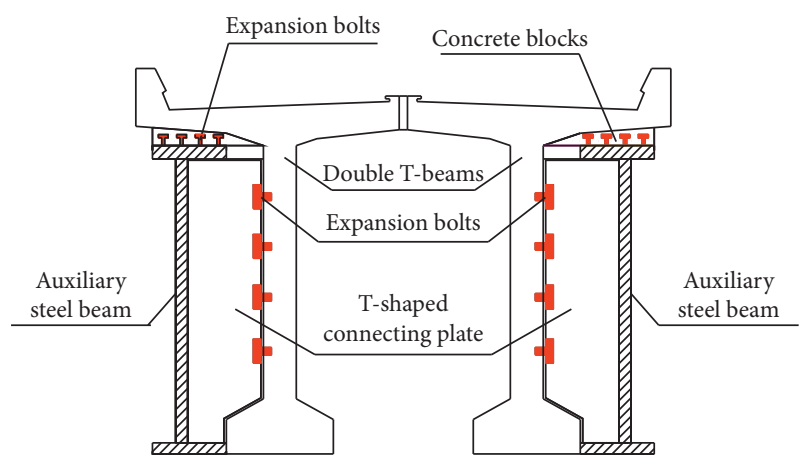

FIGURE 2: Structural diagram of auxiliary steel beam.

$$
E_{S} A_{S}+E_{T} A_{T 1}=E_{S} A_{S 2} .
$$

In formula (12), $E_{S}$ represents T-beam concrete elastic modulus (before equivalent); $A_{S}$ represents $T$-beam concrete section area (before equivalent); $E_{T}$ represents elastic modulus of auxiliary steel beam (before equivalent); $A_{T 1}$ represents auxiliary steel beam section area (before equivalent); and $A_{S 2}$ represents $\mathrm{T}$-beam concrete section area (after equivalent).

Similarly, according to the principle of equivalent bending stiffness of components, the equivalent calculation formula for bending stiffness can be listed as shown in the following equation:

$$
I_{T S}=I_{S}
$$

In formula (13), $I_{T S}$ represents moment of inertia of steel-concrete composite beam section (before equivalent); $I_{S}$ represents moment of inertia concrete section (after equivalent).

According to the above principles, the auxiliary steel beam can be equivalent to a concrete beam, and the equivalent section characteristics are shown in the following equations:

$$
\begin{aligned}
\frac{E_{T}}{E_{S}} A_{T 1} & =A_{S 2}, \\
A_{S 2} & =2 B_{1} H_{1}+B_{2} H_{2}, \\
I_{x} & =\frac{1}{12}\left\{B_{1}\left(2 H_{1}+H_{2}\right)^{3}-\left(B_{1}-B_{2}\right) H_{2}^{3}\right\}, \\
I_{y} & =\frac{1}{12}\left\{B_{1}^{3}\left(2 H_{1}+H_{2}\right)-\left(B_{1}-B_{2}\right)^{3} H_{2}\right\} .
\end{aligned}
$$

In formulae (14) to (17), $I_{x}$ represents auxiliary steel beam $X$-direction section moment of inertia (before equivalent); $I_{y}$ represents sectional moment of inertia in the $Y$-direction of auxiliary steel beam (before equivalent); $B_{1}$ represents the width of the upper and lower flanges of the auxiliary steel beam (after equivalent); $B_{2}$ represents the auxiliary steel beam web width (after equivalent); $H_{1}$ represents the height of the upper and lower flanges of the auxiliary steel beam (after equivalent); and $H_{2}$ represents auxiliary steel beam web height (after equivalent).

When calculating the transverse moment of inertia of the whole steel-concrete section, the height of the auxiliary steel beam is kept unchanged, and the width of the auxiliary steel beam is equivalent to the height of the auxiliary steel beam according to the ratio of the elastic modulus of the concrete and the steel. Similarly, the vertical moment of inertia is calculated by changing the height of the auxiliary steel beam according to the ratio of elastic modulus. Therefore, taking the equivalent section parameters of auxiliary steel beam and the original $T$-beam as a whole, the transverse and vertical moment of inertia of $T$-beam strengthened by auxiliary steel beam is calculated.

In this paper, the concrete grade of $T$-beam is C50, and the elastic modulus $E_{S}=34.5 \mathrm{GPa}$; 235 steel is used as auxiliary steel beam, and its elastic modulus $E_{T}=206 \mathrm{GPa}$; thus, $E_{T} / E_{S}=5.971$. Then, the cross-sectional characteristics of $T$-beam before and after reinforcement of auxiliary steel 
beam are obtained by using the equivalent principle which are picked up as shown in Table 2 .

2.3. Model Validation. To verify the reliability of the model, the calculation condition in [11] is taken as an example. The equivalent section characteristics of T-beam before and after reinforcement are input into FTTB system, respectively. The train is composed of $1 \mathrm{DF} 4$ locomotive and $12 \mathrm{C} 80$ wagons with the speed of $70 \mathrm{~km} / \mathrm{h}$. Seven-span $32 \mathrm{~m}$ concrete simple supported beam and single-line bridge are selected as the calculation object. The straight bridge and ballasted track are $60 \mathrm{~kg} / \mathrm{m}$ rail, type II concrete sleeper and crushed stone ballast. $K_{1}=2.9 \times 10^{7} \mathrm{~N} / \mathrm{m}, \quad K_{2}=1.1 \times 10^{8} \mathrm{~N} / \mathrm{m}, \quad K_{4}=4.0 \times 10^{6} \mathrm{~N} / \mathrm{m}$, $K_{5}=4.5 \times 10^{7} \mathrm{~N} / \mathrm{m}, K_{6}=2.1 \times 10^{9} \mathrm{~N} / \mathrm{m}$, and $K_{7}=2.5 \times 10^{11} \mathrm{~N} /$ $\mathrm{m}$. The vertical dynamic deflection and lateral amplitude of the fourth span of the auxiliary steel beam before and after reinforcement are obtained through calculation, and the results are shown in Table 3 . For the convenience of analysis, the test values [11] in the literature are also listed in Table 3.

Table 3 shows that the vertical dynamic deflection and transverse amplitude of the beam before reinforcement are $12.38 \mathrm{~mm}$ and $1.14 \mathrm{~mm}$ respectively, and the vertical dynamic deflection and transverse amplitude of the beam after reinforcement are $11.47 \mathrm{~mm}$ and $0.93 \mathrm{~mm}$, respectively, which are basically consistent with the experimental values in [11]. It can be seen that the calculation model in this paper is reliable. In addition, to directly reflect the reinforcement effect of the auxiliary steel beam, the vertical dynamic deflection and transverse amplitude time history curves of the beam body are listed here, as shown in Figures 3 and 4 .

\section{Evaluation Method of Auxiliary Steel Beam Reinforcement Based on Running Safety and Dynamic Response}

Derailment coefficient and wheel load reduction rate are traditional safety indicators for evaluating train operation [20]. However, the studies have shown $[15,16,21]$ that derailment coefficient and wheel load reduction rate do not have a control effect on train derailment. It is difficult to ensure that the abovementioned safety indicators do not exceed the specification limit requirements during train operation. In [16], a criterion for judging the lateral vibration stability of FTTB system based on the idea of energy increment is proposed, that is, $\Delta \sigma \mathrm{cr}>\Delta \sigma \mathrm{pr}$, the lateral vibration of FTTB system is stable; $\Delta \sigma c r<\Delta \sigma \mathrm{pr}$, the lateral vibration of FTTB system is unstable; $\Delta \sigma c r=\Delta \sigma p$, the lateral vibration of FTTB system is in critical state of instability, so this paper deals with it.

In the criterion of lateral vibration stability of FTTB system, $\Delta \sigma p r$ represents the increment of input energy of lateral vibration of FTTB system. The research shows that the bogie frame hunting wave is used as the lateral vibration excitation source of the FTTB system [16], and the standard deviation $\sigma_{p}$ of the bogie frame hunting wave is used as the input energy to cause the lateral vibration of the FTTB system. The relationship curve between the freight car speed $V$ and the standard deviation $\sigma_{p}$ with a $99 \%$ probability level (i.e., " $\sigma_{p}-V$ curve") is obtained through statistics and calculation. On this basis, according to the method described in [22], the standard deviation $\sigma_{p}$ of the bogie frame hunting wave above $90 \mathrm{~km} / \mathrm{h}$ is obtained to form the $\sigma_{p}-V$ curve, as shown in Figure 5.

Figure 5 shows that the input energy of FTTB system will rise gradually with the increase of the speed $V$. The increment of the energy input into FTTB system $\Delta \sigma_{\mathrm{pr}}$ can be expressed as the difference of the input energy of system between $\sigma_{\mathrm{pr}}$ and $\sigma_{p 0}$ when the speed is raised from $V_{0} \mathrm{~km} / \mathrm{h}$ to $V_{\mathrm{r}} \mathrm{km} / \mathrm{h}$, that is, $\Delta \sigma_{\mathrm{pr}}=\sigma_{\mathrm{pr}}-\sigma_{p 0}$. However, $\sigma_{p}$ was measured under normal driving condition, reflecting the input energy of FTTB system in normal driving condition, while the maximum input energy is not present. The input energy of FTTB system is the biggest when the train left the rails, namely, $\sigma_{p \max }$. While the input energy larger than $\sigma_{p \max }$ does not exist, the FTTB system loses stability due to lateral vibration when the train derails. However, it is difficult to measure the bogie frame hunting wave because of the small probability of the train derailment, and the derailment test is hard to operate. But, according to the principle of work-energy transformation, the greater the energy input is, the greater the response of the FTTB system vibration is generated. Actually, the graph of $\sigma_{p \max }-V$ must be higher than the graph of $\sigma_{p}-V$ because $\sigma_{p \max }$ is much larger than $\sigma_{p}$. Although the graph of $\sigma_{p \max }-V$ is difficult to build, the literature [16] documents the theory that $\sigma_{p \max }-$ $V$ curve is parallel to the $\sigma_{p}-V$ curve.

Then, the calculation formula of energy increment can be listed, respectively, according to the graph of $\sigma_{p \max }-V$ and $\sigma_{p}-V$. Formulae (18) and (19) are as follows:

$$
\begin{gathered}
\Delta \sigma_{\mathrm{pr}, \text { max }}=\sigma_{\mathrm{pr}, \text { max }}-\sigma_{p 0, \text { max }}=\frac{\partial \sigma_{p \max }}{\partial V} \Delta V, \\
\Delta \sigma_{\mathrm{pr}}=\sigma_{\mathrm{pr}}-\sigma_{p 0}=\frac{\partial \sigma_{p}}{\partial V} \Delta V .
\end{gathered}
$$

In formulae (18) and (19), $\sigma_{p 0}$ and $\sigma_{\mathrm{pr}}$ are the energy of lateral vibration input into the FTTB system under the normal driving at the speed of $V_{0}$ and $V_{r}$, respectively; $\Delta V=V_{r}-V_{0} ; \sigma_{p 0 \max }$ and $\sigma_{\mathrm{pr}, \max }$ are the maximum energy of lateral vibration input into the FTTB system at the speed of $V_{0}$ and $V_{r}$ when derailment occurs, respectively. According to the principle of parallel curve, the slope of $\sigma_{p \max }-V$ curve is equal to the slope of $\sigma_{p}-V$ curve; we can obtain the following formula:

$$
\frac{\partial \sigma_{p \max }}{\partial V}=\frac{\partial \sigma_{p}}{\partial V} .
$$

Formula (20) indicates $\Delta \sigma_{\mathrm{pr}, \max }=\Delta \sigma_{\mathrm{pr}}$; that is to say, the maximum energy increment of lateral vibration input into the FTTB system when derailment occurs can be acquired from the energy increment of lateral vibration input into the FTTB system under normal driving condition.

At the same time, $\Delta \sigma_{\mathrm{cr}}$ is the lateral vibration ultimate resistance work increment of FTTB system. The ultimate resistance work of the system refers to the maximum energy input into the system. The much more energy has not existed 
TABLE 2: Cross-sectional characteristics of T-beam before and after reinforcement of auxiliary steel beam.

\begin{tabular}{lcc}
\hline Reinforcement state & Cross moment of inertia along $X\left(\mathrm{~m}^{4}\right)$ & Cross moment of inertia along $Y\left(\mathrm{~m}^{4}\right)$ \\
\hline Before reinforcement & 1.1104 & 0.1708 \\
After reinforcement & 1.3881 & 0.2778 \\
\hline
\end{tabular}

TABLE 3: The calculated and experimental values of vertical dynamic deflection and transverse amplitude in the middle span of the beams before and after reinforcement.

\begin{tabular}{lcccc}
\hline Reinforced state & \multicolumn{2}{c}{ Vertical dynamic deflection $(\mathrm{mm})$} & \multicolumn{2}{c}{ Beam transverse amplitude (mm) } \\
& Calculated value & Test value [11] & Calculated value & Test value [11] \\
\hline Before reinforcement & 12.38 & 11.98 & 1.14 & 1.24 \\
After reinforcement & 11.47 & 11.02 & 0.93 & 0.94 \\
\hline
\end{tabular}

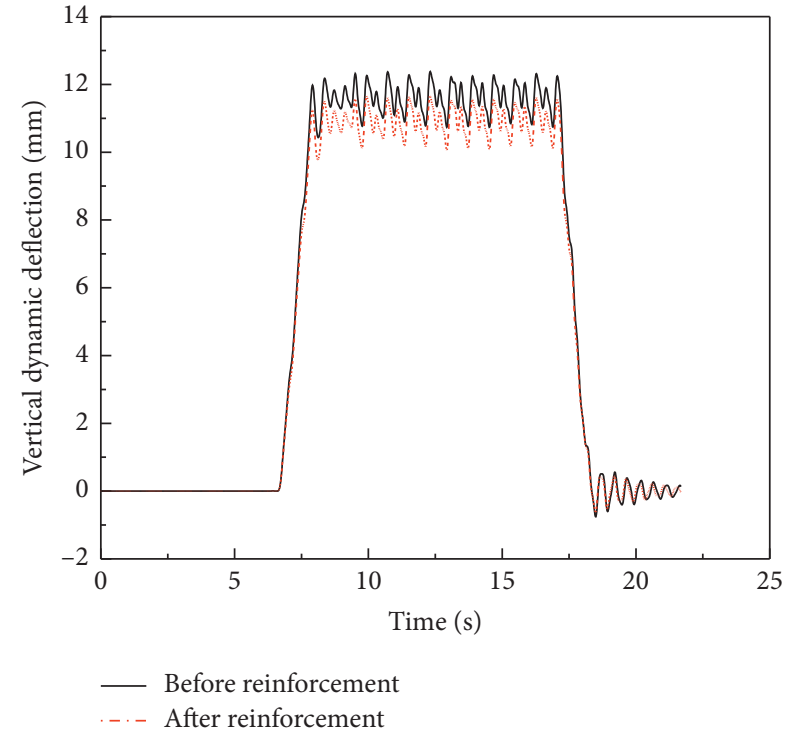

Figure 3: Vertical dynamic deflection-time history curves of auxiliary steel beam before and after reinforcement.

since the system is out of stability. Like the stability theory of compression bar, when the load is constantly applied on the top of the pressure bar, with the load increasing gradually, the maximum load is the resistance force that the pressure bar can bear. Similarly, according to the wheel derailment geometric criterion [16], the lateral vibration limit resistance work of FTTB system can be calculated by adopting the trial algorithm. From this, we can get $\sigma_{c}$ corresponding to different speeds $V$ and establish $\sigma_{c}-V$ curve. According to the difference method, $\Delta \sigma_{\text {cr }}$ can be shown in the following formula:

$$
\Delta \sigma_{\mathrm{cr}}=\frac{\partial \sigma_{\mathrm{cr}}(V)}{\partial V} \Delta V=\sigma_{\mathrm{cr}}-\sigma_{c 0} .
$$

In formula (21), $\sigma_{c 0}$ and $\sigma_{\mathrm{cr}}$ are lateral vibration ultimate resistance work of the FTTB system at the speed of $V_{0}$ and $V_{r}$, respectively; $\Delta V=V_{r}-V_{0}$.

At this point, we can determine $\Delta \sigma_{\mathrm{cr}}$ and $\Delta \sigma_{\mathrm{pr}}$ and then assess the stability of lateral vibration in the FTTB system. When $\Delta \sigma_{\mathrm{cr}}=\Delta \sigma_{\mathrm{pr}}$, the corresponding speed $V$ is called lateral vibration critical speed in the FTTB system (the

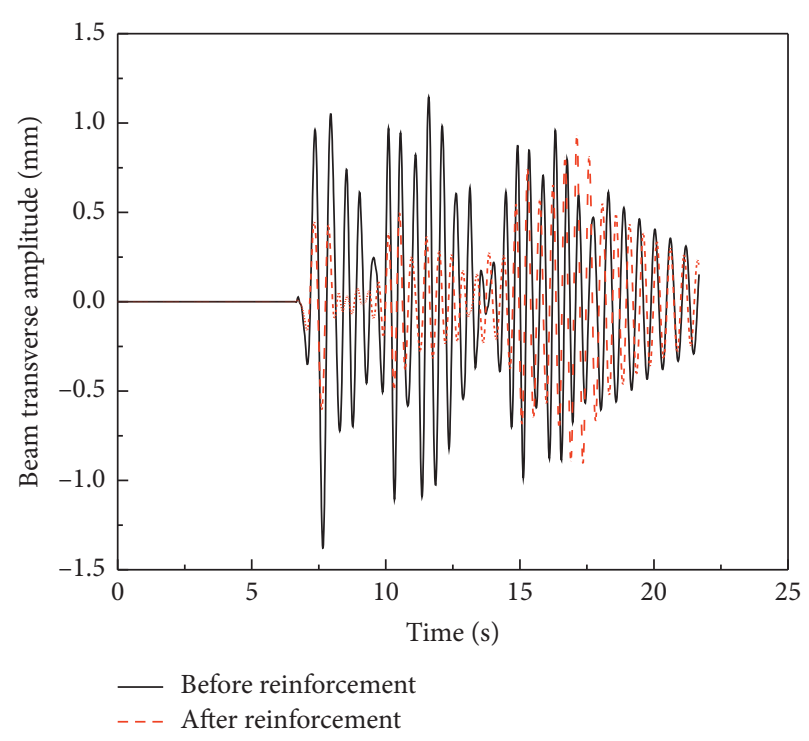

FIgURE 4: Transverse amplitude-time history curves of auxiliary steel beam before and after reinforcement.

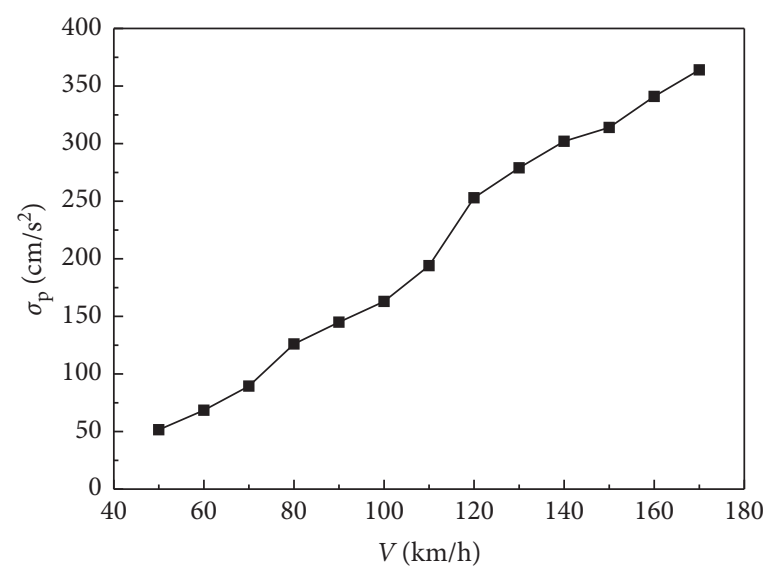

FIgURE 5: Relationship between $\sigma_{p}$ and speed $V$.

critical speed for short, $\left.V_{\mathrm{cr}}\right) . V_{L}$, the allowable limit speed, is controlled by $V_{c r} / K$. Japanese scholars adopt the safety coefficient $K=1.25$ when calculating the train running safety with derailment coefficient. This paper follows this method, 
so the allowable limit speed of the FTTB system is $V_{L}=V_{\mathrm{cr}} / 1.25$. Then, a set of quantitative indexes for assessment of train running safety including antiderailment capacity $\sigma_{c}$, critical speed $V_{c r}$, and the allowable limit speed $V_{L}$ of FTTB system are established.

Based on the above ideas, the spatial vibration response of FTTB system under normal driving condition is calculated with the actual speed $V$ less than $V_{L}$. The international standard of stability is adopted to check whether the stability of freight trains meet the requirements. Then, combined with the reinforcement measures of auxiliary steel beam, a kind of evaluation method about running safety and dynamic response of auxiliary steel beam reinforcement is put forward as shown in Figure 6.

\section{Results and Discussion}

4.1. Influence of Auxiliary Steel Beam Reinforcement on Train Running Safety. According to derailment accident and theoretical calculation results, empty vehicles are more likely to derail [22]. So, this paper takes empty freight train as an example; the formation of train is one locomotive and twelve wagons. The beam span structure before and after reinforcement of the auxiliary steel beam is consistent with Section 2.3. At the same time, because of the lack of data on the input energy of lateral vibration of FTTB system after the reinforcement of auxiliary steel beam, the input energy $\sigma_{p}$ of lateral vibration of FTTB system before and after the reinforcement should be determined according to the $\sigma_{p}-V$ curve in Figure 5. In fact, the actual input energy of the FTTB system $\sigma_{p}$ will be reduced by the reinforcement of the auxiliary steel beam. If the reinforcement of the FTTB system still adopts the input energy $\sigma_{p}$ before the reinforcement, then the actual reinforcement of the FTTB system will have a greater safety margin.

When calculating the lateral vibration stability of FTTB system, the speed of $50 \mathrm{~km} / \mathrm{h}$ is taken as the starting point. Considering calculation and test error, the lateral vibration stability of FTTB system is checked and calculated once for every $10 \mathrm{~km} / \mathrm{h}$ increase in vehicle speed. According to the evaluation method in Figure 6, the lateral vibration ultimate resistance work of FTTB system is calculated as $\sigma_{c}$, and the corresponding $\sigma_{c}-V$ curve is shown in Figure 7. Table 4 shows the calculation results of lateral vibration stability of FTTB system before and after reinforcement of auxiliary steel beam.

As shown in Figure $6, \sigma_{c}$, the lateral vibration ultimate resistance work of FTTB system before and after the reinforcement of the auxiliary steel beam increases with increased vehicle speeds $V$. The maximum value of the lateral vibration ultimate resistance work of FTTB system before the reinforcement of the auxiliary steel beam is $310 \mathrm{~cm} / \mathrm{s}^{2}$ and the maximum value of $\sigma_{c}$ after the reinforcement is $380 \mathrm{~cm} / \mathrm{s}^{2}$. The antiderailment ability of FTTB system increased by $22.6 \%$ after the reinforcement of auxiliary steel beam.

Table 4 shows that with the increase of $V$, before the reinforcement of the auxiliary steel beam, there is a certain speed $V$ that makes $\Delta \sigma_{\mathrm{cr}}=\Delta \sigma_{\mathrm{pr}}$ between 110 and $120 \mathrm{~km} / \mathrm{h}$.
According to the interpolation method, the critical speed $V_{\text {cr }}$ of lateral vibration instability of FTTB system is obtained as $115.56 \mathrm{~km} / \mathrm{h}$. Considering the safety factor of 1.25 , the corresponding allowable limit speed $V_{L}$ is obtained as $92.49 \mathrm{~km} / \mathrm{h}$. Similarly, after the reinforcement of the auxiliary steel beam, there is a certain speed $V$ that makes $\Delta \sigma_{\mathrm{cr}}=$ $\Delta \sigma_{\text {pr }}$ between 130 and $140 \mathrm{~km} / \mathrm{h}$; the corresponding critical speed of $V_{\text {cr }}$ and the corresponding allowable limit speed $V_{L}$ are $132.73 \mathrm{~km} / \mathrm{h}$ and $106.18 \mathrm{~km} / \mathrm{h}$. Obviously, the critical speed and allowable limit speed increased by $14.8 \%$ after the reinforcement of the auxiliary steel beam.

\subsection{Influence of Auxiliary Steel Beam Reinforcement on Spatial} Vibration Response of FTTB System. Taking $V_{L}$ as the upper limit before and after the reinforcement of the auxiliary steel beam in Section 4.1, the spatial vibration response of FTTB system under the condition of empty and loaded train (meaning, $V<V_{L}$ ) are calculated. The calculated speed is $60 \sim 90 \mathrm{~km} / \mathrm{h}$, and the formation of train and the structure of beam span is consistent with Section 2.3. Considering the limit of page, some major indicators are analyzed. Among them, $B_{h}$ and $B_{v}$ represent the lateral amplitude and vertical dynamic deflection of the middle span of the 4 th beam body, respectively; $C_{h}$ and $C_{v}$ represent the car body transverse and vertical displacement of the 5th wagon, respectively; $T_{p}$ and $D_{w}$ represent the derailment coefficient and wheel reduction rate of the 1st axis of the 5th wagon, respectively; and $S_{h}$ and $S_{v}$ represent the horizontal and vertical Sperling stability indexes of the 5th wagon. The maximum value of the above indicators was shown in Table 5. In Table 5, V, RS, E, L, A, and $B$ represent speed, reinforcement state, empty wagon, and loaded wagon after and before reinforcement, respectively. At the same time, the column diagrams corresponding to the indicators in Table 5 are listed as shown in Figures $8 \sim 13$.

Figure 8 reflects the changing trend of $B_{h}$ with the action of empty and loaded wagon along with $V$. In Figure 8, before and after reinforcement, $B_{h}$ increases with the increase of $V$. When $V$ is $90 \mathrm{~km} / \mathrm{h}, B_{h}$ with the action of empty wagon before and after reinforcement is $3.15 \mathrm{~mm}$ and $2.77 \mathrm{~mm}$, respectively. $B_{h}$ decreases by $12.1 \%$ after reinforcement. Meanwhile, $B_{h}$ with the action of loaded wagon before and after reinforcement is $1.72 \mathrm{~mm}$ and $1.64 \mathrm{~mm}$, respectively. $B_{h}$ decreases by $4.6 \%$ after reinforcement. It is shown that $B_{h}$ with the action of empty wagon is greater than action of loaded wagon, and the auxiliary steel beam reinforcement has the function of reducing transverse vibration of the beam body with the action of empty wagon.

Figure 9 reflects the changing trend of $B_{v}$ with the action of empty and loaded wagon along with $V$. In Figure 9, before and after the reinforcement, $B_{v}$ changes with the increase of $V$. When $V$ is $90 \mathrm{~km} / \mathrm{h}, B_{v}$ with the action of empty wagon before and after reinforcement is $3.71 \mathrm{~mm}$ and $3.49 \mathrm{~mm}$, respectively. $B_{v}$ decreases by $5.9 \%$ after reinforcement. Meanwhile, $B_{v}$ with the action of loaded wagon before and after reinforcement is $15.14 \mathrm{~mm}$ and $13.53 \mathrm{~mm}$, respectively. $B_{v}$ decreases by $10.6 \%$ after 


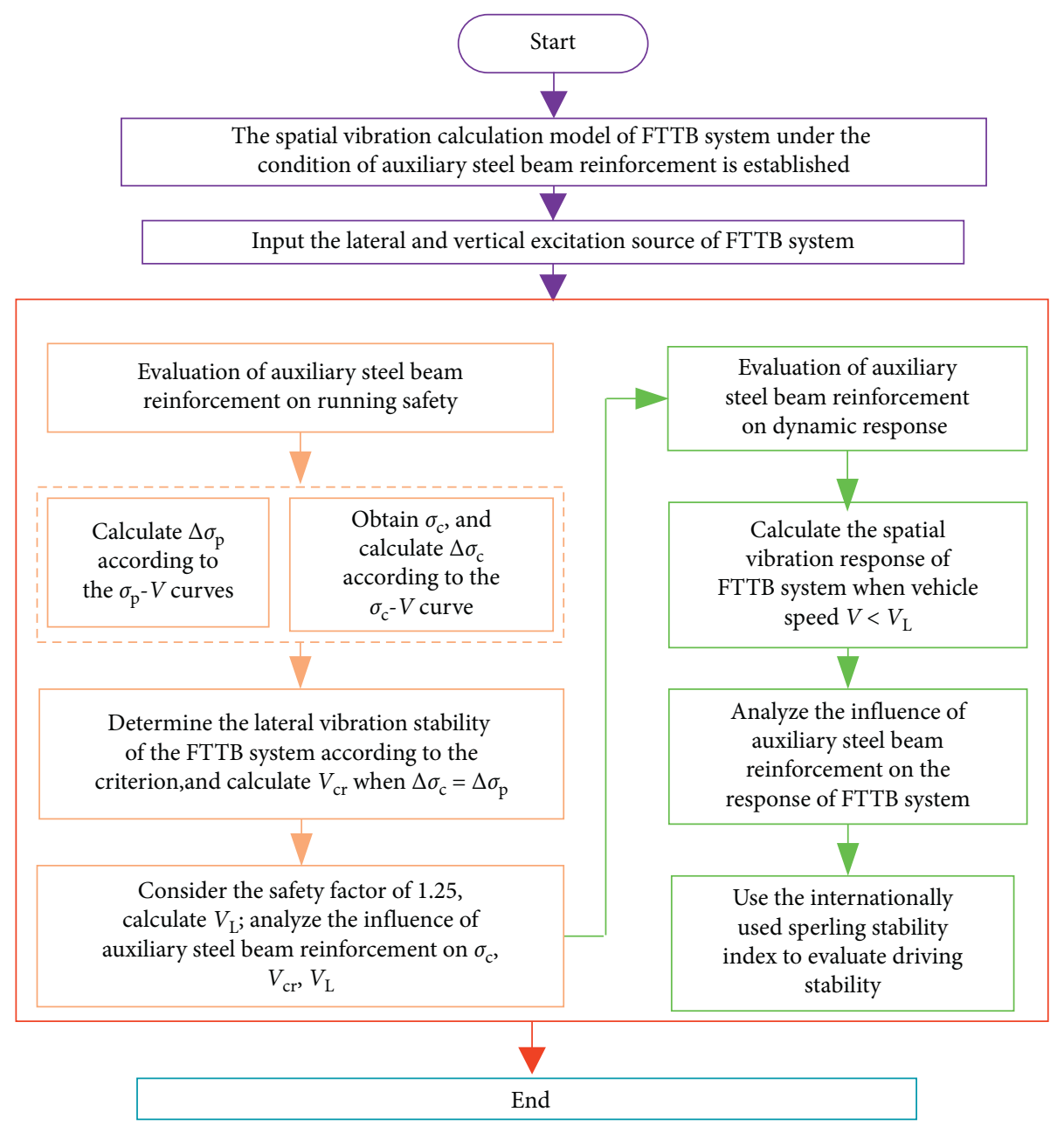

FIgURE 6: Evaluation method about running safety and dynamic response of auxiliary steel beam reinforcement.

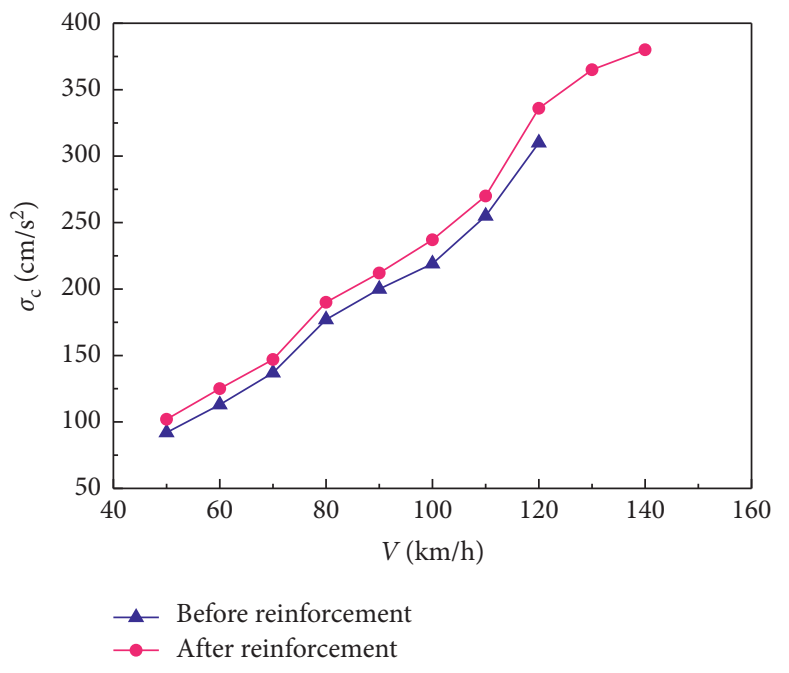

Figure 7: Relationship $\sigma_{c}$ and $V$ before and after the reinforcement of auxiliary steel beams.

reinforcement. It is shown that $B_{v}$ with the action of loaded wagon is greater than with the action of empty wagon, and the auxiliary steel beam reinforcement has the function of reducing vertical dynamic deflection of the beam body with the action of loaded wagon.

Figure 10 reflects the changing trend of $C_{h}$ under the action of empty and loaded wagon with $V$. In Figure 10, before and after the reinforcement, $C_{h}$ increases with the increase of $V$. When $V$ is $90 \mathrm{~km} / \mathrm{h}, C_{h}$ with the action of empty wagon before and after reinforcement is $45.83 \mathrm{~mm}$ and $42.51 \mathrm{~mm}$, respectively. $C_{h}$ decreases by $7.2 \%$ after reinforcement. Meanwhile, $C_{h}$ with the action of loaded wagon before and after reinforcement is $31.81 \mathrm{~mm}$ and $30.27 \mathrm{~mm}$, respectively. $C_{h}$ decreases by $4.8 \%$ after reinforcement. It is shown that $C_{h}$ with the action of empty wagon is greater than with the action of loaded wagon, and the auxiliary steel beam reinforcement has the function of reducing the lateral displacement of the car body with the action of empty wagon.

Figure 11 reflects the changing trend of $C_{v}$ under the action of empty and loaded wagon with the change of $V$. In Figure 11, before and after the reinforcement, $C_{v}$ increases with the increase of $V$. When $V$ is $90 \mathrm{~km} / \mathrm{h}, C_{v}$ with the action of empty wagon before and after reinforcement is $3.27 \mathrm{~mm}$ and $3.11 \mathrm{~mm}$, respectively. $C_{v}$ decreases by $4.8 \%$ after reinforcement. Meanwhile, $C_{v}$ with the action of loaded wagon before and after reinforcement is $13.14 \mathrm{~mm}$ and 
TABLE 4: Calculation results of lateral vibration stability of FTTB system before and after the auxiliary steel beams reinforcement.

\begin{tabular}{|c|c|c|c|c|c|c|c|c|c|c|}
\hline \multirow{2}{*}{$\begin{array}{l}V \\
(\mathrm{~km} / \mathrm{h})\end{array}$} & \multirow{2}{*}{$\begin{array}{c}\sigma_{p} \\
\left(\mathrm{~cm} / \mathrm{s}^{2}\right)\end{array}$} & \multirow{2}{*}{$\begin{array}{c}\Delta \sigma_{p} \\
\left(\mathrm{~cm} / \mathrm{s}^{2}\right)\end{array}$} & \multicolumn{4}{|c|}{ Before reinforcement } & \multicolumn{4}{|c|}{ After reinforcement } \\
\hline & & & $\begin{array}{c}\sigma_{c} \\
\left(\mathrm{~cm} / \mathrm{s}^{2}\right)\end{array}$ & $\begin{array}{c}\Delta \sigma_{c} \\
\left(\mathrm{~cm} / \mathrm{s}^{2}\right)\end{array}$ & $\Delta \sigma_{c}-\Delta \sigma_{p}$ & Whether stable & $\begin{array}{c}\sigma_{c} \\
\left(\mathrm{~cm} / \mathrm{s}^{2}\right)\end{array}$ & $\begin{array}{c}\Delta \sigma_{c} \\
\left(\mathrm{~cm} / \mathrm{s}^{2}\right)\end{array}$ & $\Delta \sigma_{c}-\Delta \sigma_{p}$ & Whether stable \\
\hline 140 & 302 & 23 & - & - & - & - & 380 & 15 & $<0$ & No \\
\hline 130 & 279 & 26 & - & - & - & - & 365 & 29 & $>0$ & Yes \\
\hline 120 & 253 & 59 & 310 & 55 & $<0$ & No & 336 & 66 & $>0$ & Yes \\
\hline 110 & 194 & 31 & 255 & 36 & $>0$ & Yes & 270 & 33 & $>0$ & Yes \\
\hline 100 & 163 & 18 & 219 & 19 & $>0$ & Yes & 237 & 25 & $>0$ & Yes \\
\hline 90 & 145 & 19 & 200 & 23 & $>0$ & Yes & 212 & 22 & $>0$ & Yes \\
\hline 80 & 126 & 36.6 & 177 & 40 & $>0$ & Yes & 190 & 43 & $>0$ & Yes \\
\hline 70 & 89.4 & 20.9 & 137 & 24 & $>0$ & Yes & 147 & 22 & $>0$ & Yes \\
\hline 60 & 68.5 & 17.0 & 113 & 21 & $>0$ & Yes & 125 & 23 & $>0$ & Yes \\
\hline 50 & 51.5 & - & 92 & - & - & - & 102 & - & - & - \\
\hline
\end{tabular}

TABLE 5: Vibration responses calculation results of FTTB system under the action of empty and loaded wagon before and after reinforcement.

\begin{tabular}{lccccccccccccccccc}
\hline \multirow{2}{*}{$V / \mathrm{km} / \mathrm{h}$} & $\mathrm{RS}$ & \multicolumn{2}{c}{$B_{h} / \mathrm{mm}$} & \multicolumn{2}{c}{$B_{v} / \mathrm{mm}$} & \multicolumn{2}{c}{$C_{h} / \mathrm{mm}$} & \multicolumn{2}{c}{$C_{v} / \mathrm{mm}$} & \multicolumn{2}{c}{$D_{w}$} & \multicolumn{2}{c}{$T_{p}$} & \multicolumn{2}{c}{$S_{h}$} & \multicolumn{2}{c}{$S_{v}$} \\
& & $\mathrm{E}$ & $\mathrm{L}$ & $\mathrm{E}$ & $\mathrm{L}$ & $\mathrm{E}$ & $\mathrm{L}$ & $\mathrm{E}$ & $\mathrm{L}$ & $\mathrm{E}$ & $\mathrm{L}$ & $\mathrm{E}$ & $\mathrm{L}$ & $\mathrm{E}$ & $\mathrm{L}$ & $\mathrm{E}$ & $\mathrm{L}$ \\
\hline \multirow{2}{*}{60} & $\mathrm{~A}$ & 2.12 & 0.88 & 3.07 & 11.74 & 26.37 & 23.25 & 2.77 & 11.14 & 0.57 & 0.49 & 1.54 & 0.98 & 4.11 & 3.45 & 2.39 & 3.18 \\
& $\mathrm{~B}$ & 1.73 & 0.55 & 2.78 & 10.52 & 22.87 & 21.71 & 2.58 & 10.63 & 0.48 & 0.43 & 1.37 & 0.86 & 3.72 & 3.09 & 2.14 & 2.92 \\
\hline \multirow{2}{*}{70} & $\mathrm{~A}$ & 2.20 & 1.15 & 3.25 & 12.38 & 30.23 & 26.16 & 2.83 & 11.81 & 0.62 & 0.59 & 1.62 & 1.07 & 4.32 & 3.75 & 2.46 & 3.37 \\
& $\mathrm{~B}$ & 1.81 & 0.93 & 2.98 & 11.48 & 27.32 & 24.76 & 2.68 & 11.18 & 0.54 & 0.49 & 1.45 & 1.01 & 3.97 & 3.49 & 2.38 & 3.06 \\
\hline \multirow{2}{*}{80} & $\mathrm{~A}$ & 2.52 & 1.49 & 3.61 & 13.46 & 37.31 & 29.85 & 2.99 & 12.31 & 0.77 & 0.64 & 1.76 & 1.19 & 4.43 & 3.96 & 2.63 & 3.53 \\
& $\mathrm{~B}$ & 2.18 & 1.41 & 3.32 & 11.52 & 34.12 & 28.02 & 2.84 & 11.64 & 0.69 & 0.52 & 1.59 & 1.14 & 4.11 & 3.67 & 2.43 & 3.28 \\
\hline \multirow{2}{*}{90} & $\mathrm{~A}$ & 3.15 & 1.72 & 3.71 & 15.14 & 45.83 & 31.81 & 3.27 & 13.14 & 0.85 & 0.70 & 1.93 & 1.29 & 4.54 & 4.13 & 2.79 & 3.64 \\
& $\mathrm{~B}$ & 2.77 & 1.64 & 3.49 & 13.53 & 42.51 & 30.27 & 3.11 & 12.63 & 0.78 & 0.57 & 1.77 & 1.23 & 4.23 & 3.86 & 2.62 & 3.39 \\
\hline
\end{tabular}
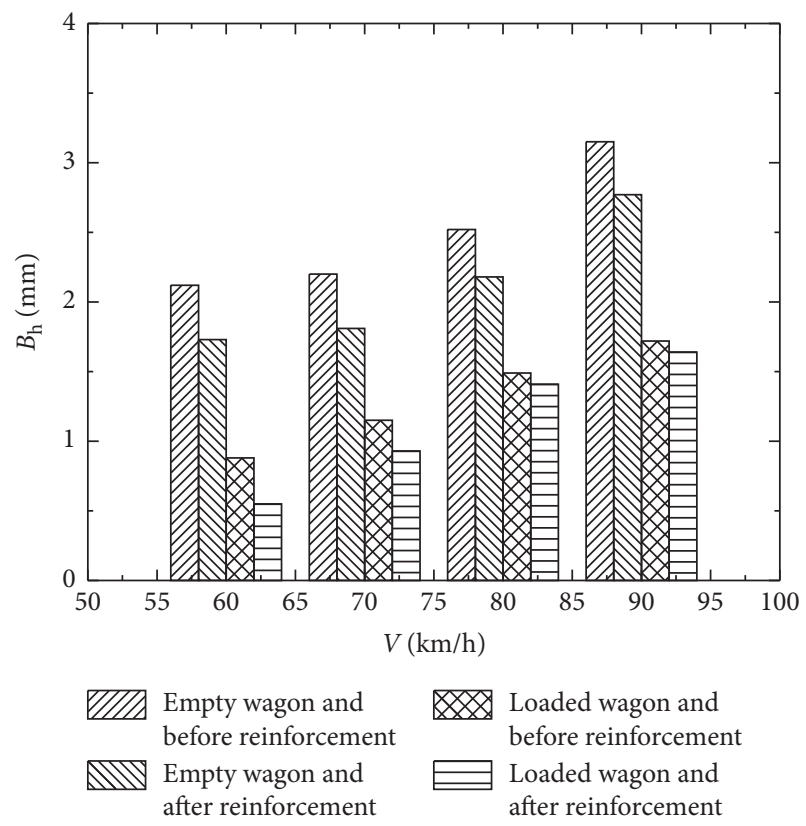

Figure 8: $B_{h}$ change with $V$.

$12.63 \mathrm{~mm}$, respectively. $C_{v}$ decreases by $3.9 \%$ after reinforcement. It is shown that $C_{v}$ with the action of loaded wagon is greater than with the action of empty wagon, and the auxiliary steel beam reinforcement has the function of

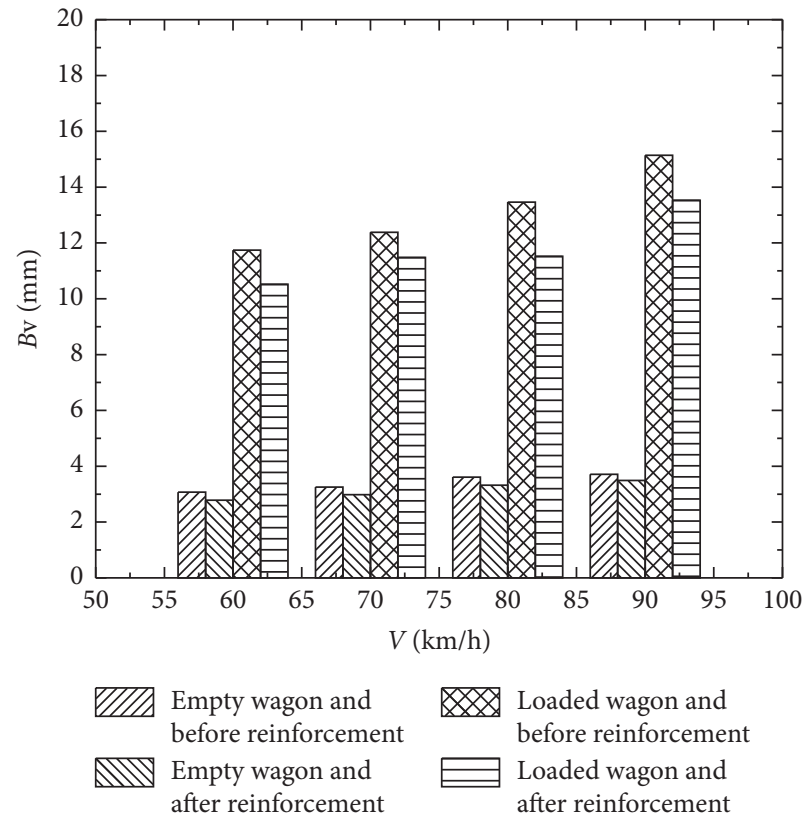

Figure 9: $B_{v}$ change with $V$.

reducing the lateral displacement of the car body with the action of loaded wagon.

Figures 12 and 13, respectively, reflect the changing trend of $D_{w}$ and $T_{p}$ under the action of empty and loaded 

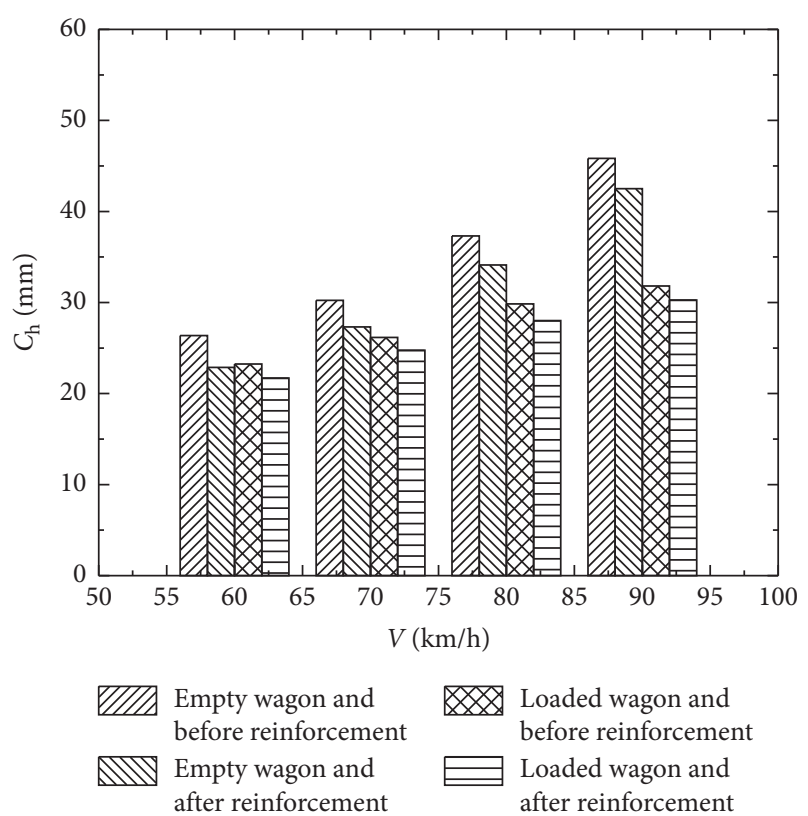

Figure 10: $C_{h}$ change with $V$.
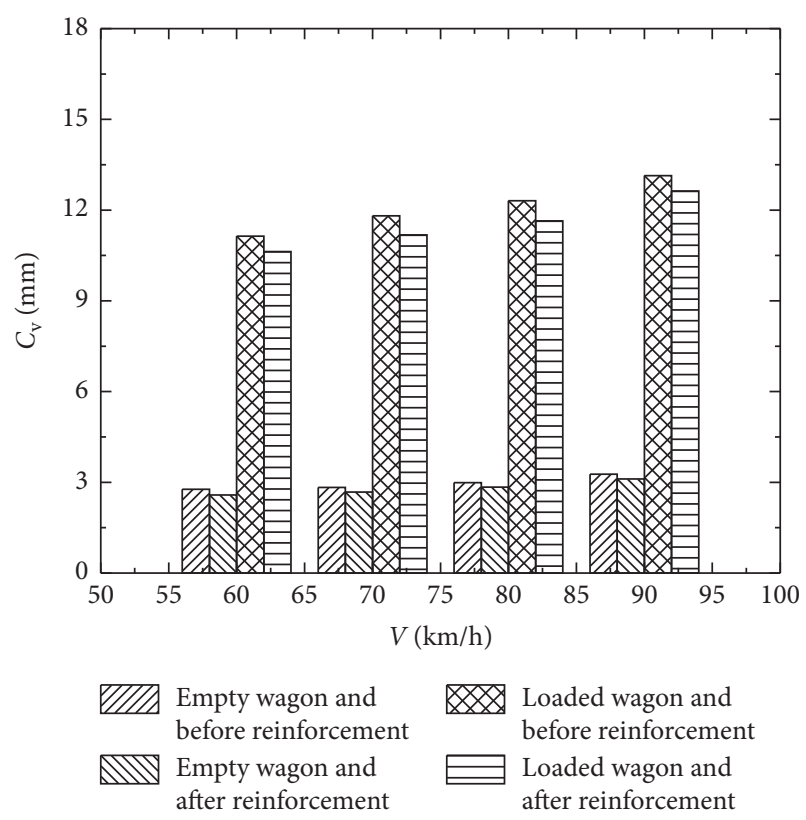

Figure 11: $C_{v}$ change with $V$.

wagon with the change of $V$. In Figures 12 and 13, before and after the reinforcement, $D_{w}$ and $T$ increase with $V$. When $V$ is $90 \mathrm{~km} / \mathrm{h}, D_{w}$ with the action of empty wagon before and after reinforcement is 0.85 and 0.78 , respectively, and $T_{p}$ is 1.93 and 1.77 , respectively. $D_{w}$ and $T_{\mathrm{p}}$ both exceeded the limits of 0.65 and 1.0 [20]. $D_{w}$ and $T_{p}$ decrease by $8.2 \%$ and $8.3 \%$ after reinforcement, respectively. Meanwhile, when $V$ is $90 \mathrm{~km} / \mathrm{h}, D_{w}$ with the action of loaded wagon before and after reinforcement is 0.70 and 0.57 , respectively, and $T_{p}$ is 1.29 and 1.23 , respectively. $D_{w}$ and $T_{p}$ both exceeded the limits of 0.65 and 1.0 [20] except for $D_{w}$ after reinforcement. $D_{w}$ and $T_{p}$ decrease by $18.5 \%$ and $4.6 \%$ after reinforcement.

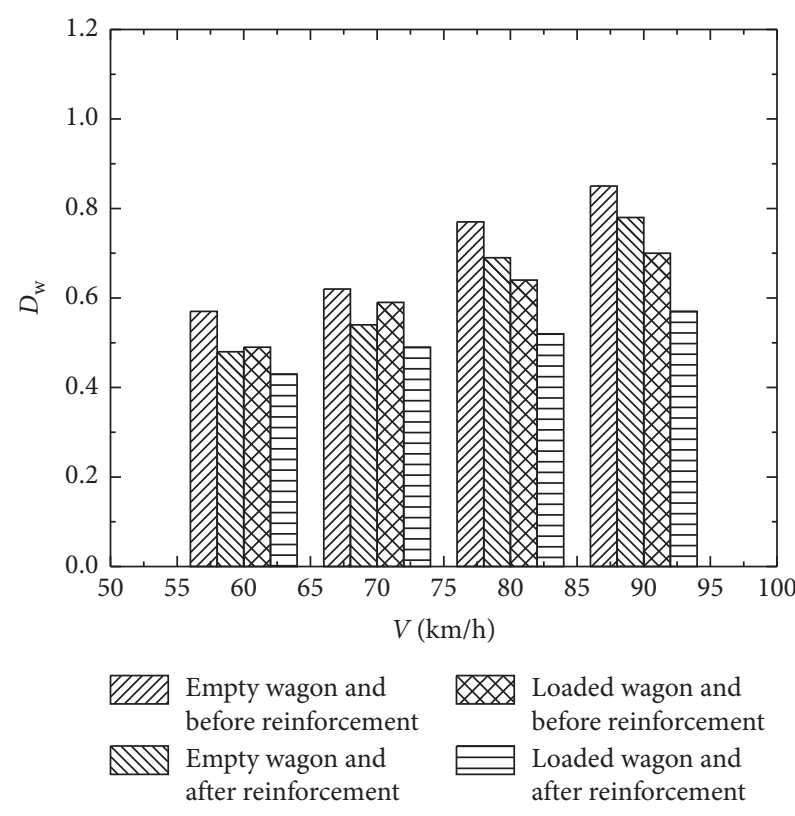

Figure 12: $D_{w}$ change with $V$.
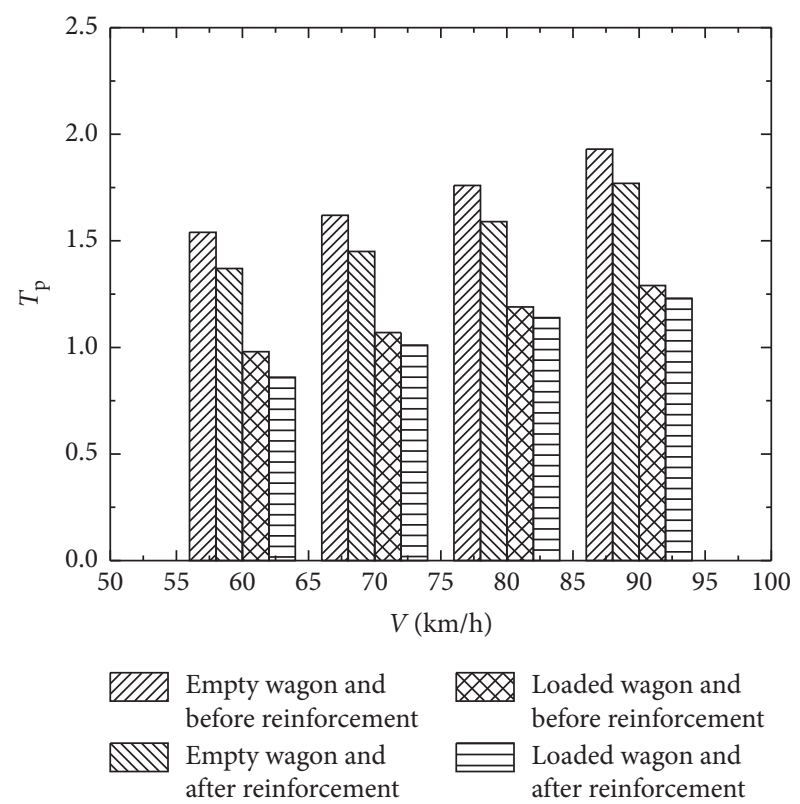

Figure 13: $T_{p}$ change with $V$.

It can be seen that the wheel load reduction rate and derailment coefficient limit are difficult to determine whether a train wheel is derailed, but it can indicate that the greater the wheel load reduction rate and derailment coefficient, the more unsafe. $D_{w}$ and $T_{p}$ with the action of empty wagon are greater than with the action of loaded wagon, and reinforcement measures have a certain effect on reducing wheel load reduction rate and derailment coefficient.

Figures 14 and 15, respectively, reflect the changing trend of $S_{h}$ and $S_{v}$ under the action of empty and loaded wagon with the change of $V$. In Figures 14 and 15, before and after the reinforcement, $S_{h}$ and $S_{v}$ increase with the increase 

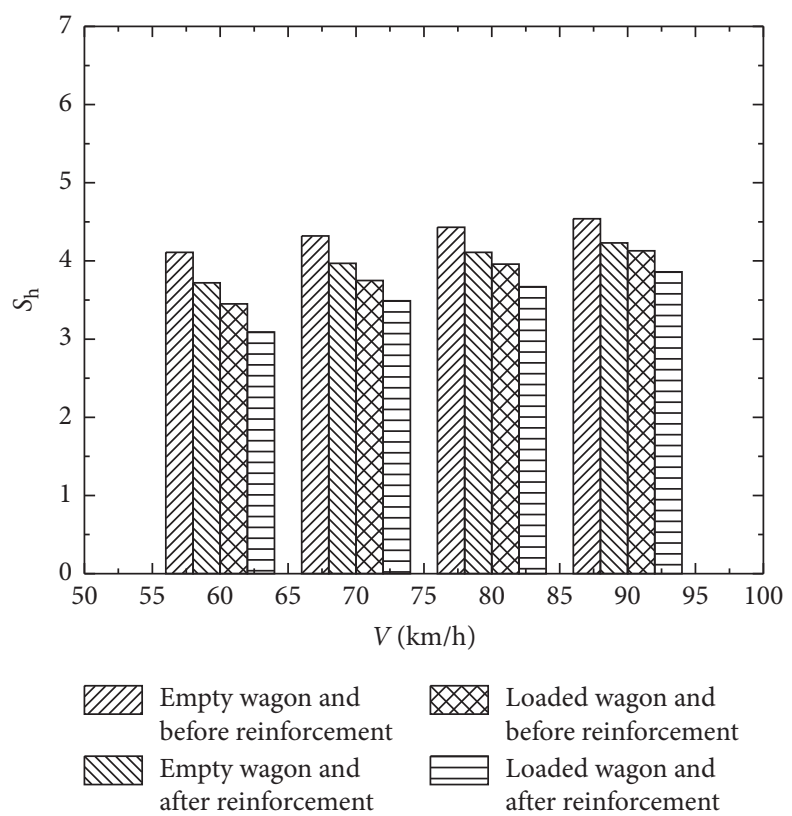

FIgURE 14: $S_{h}$ change with $V$.

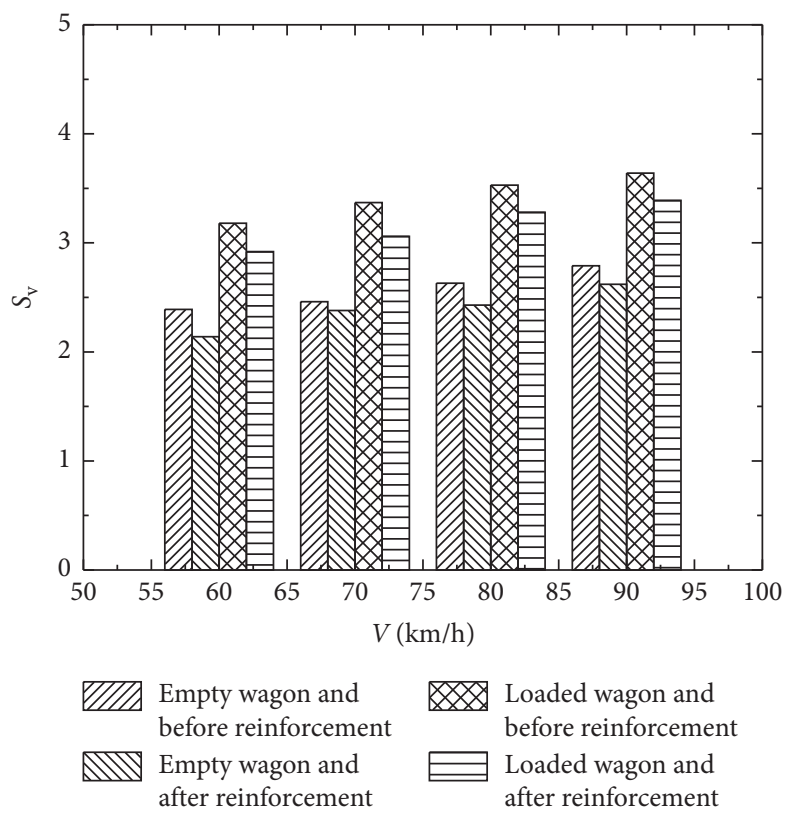

FIgURE 15: $S_{v}$ change with $V$.

of $V$. When $V$ is $90 \mathrm{~km} / \mathrm{h}, S_{h}$ with the action of empty wagon before and after reinforcement is 4.54 and 4.23 , respectively, and $S_{v}$ is 2.79 and 2.62 , respectively. $S_{h}$ and $S_{v}$ decrease by $6.8 \%$ and $6.1 \%$ after reinforcement, respectively. It can be seen that $S_{h}$ exceeds the specification limit of 4.25 [20] when $V$ is $90 \mathrm{~km} / \mathrm{h}$, and after the reinforcement, $S_{h}$ is less than the specification limit, indicating that the auxiliary steel beam reinforcement can meet the requirements of the train running stability. Meanwhile, $S_{h}$ and $S_{v}$ are within the limit value before and after reinforcement under the action of loaded wagon. It can be seen that the running stability of loaded wagon is better than that of empty wagon. 


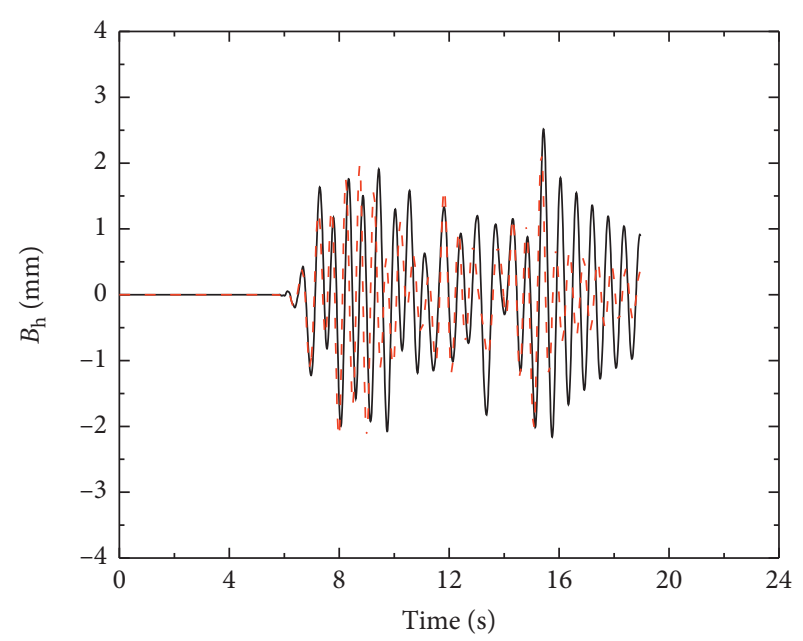

— Before reinforcement

- - - After reinforcement

(a)

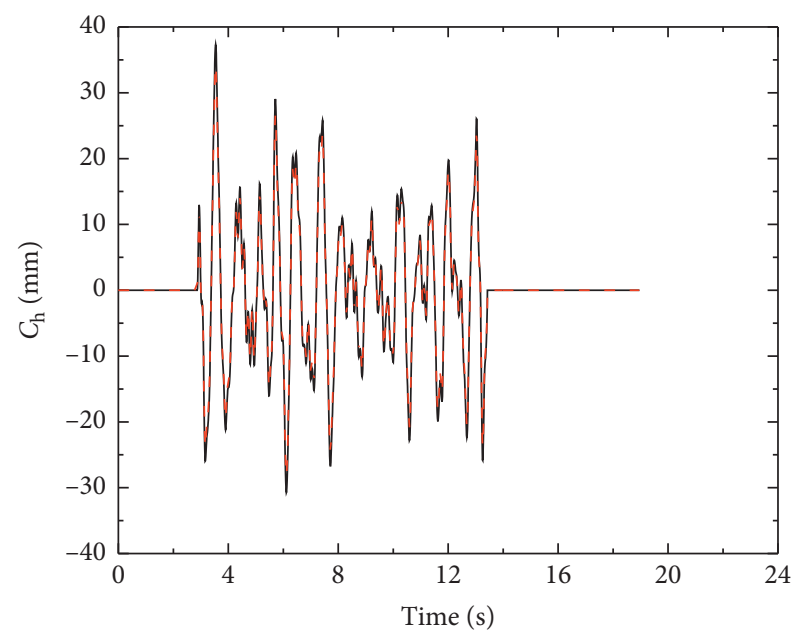

_ Before reinforcement

- - - After reinforcement

(c)

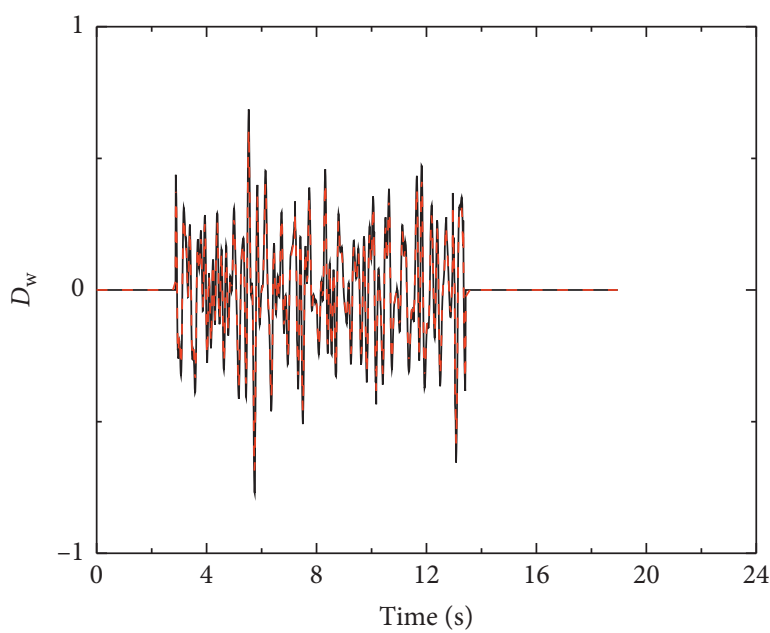

- Before reinforcement

- - - After reinforcement

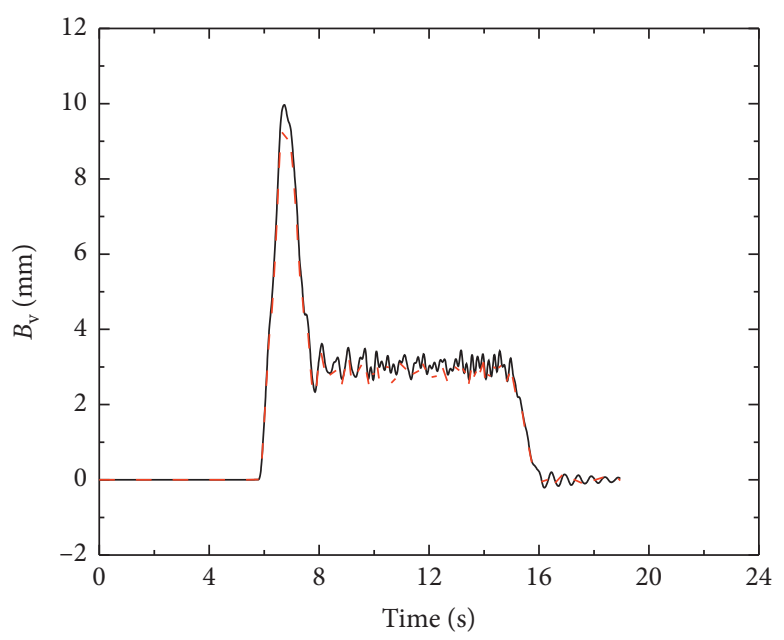

- Before reinforcement - - - After reinforcement

(b)

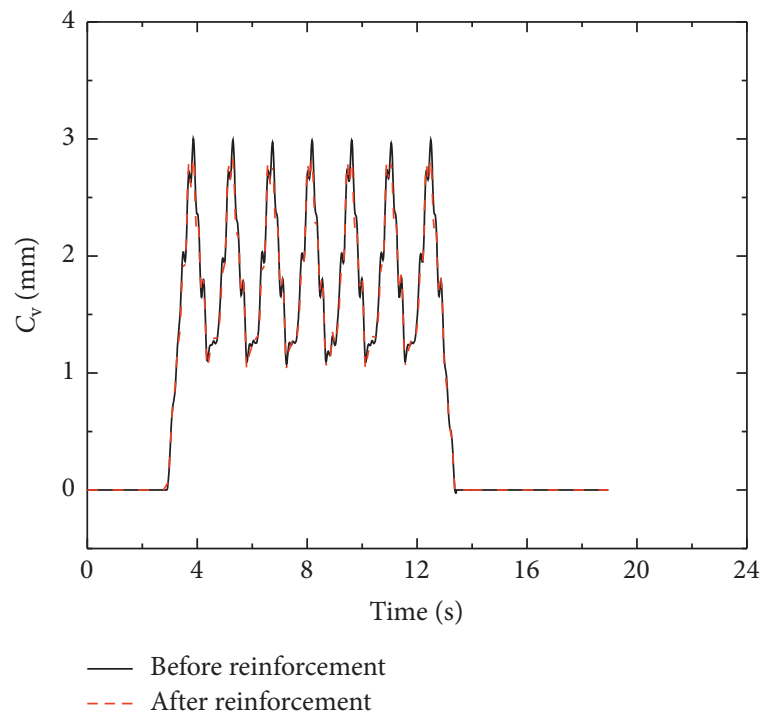

(d)

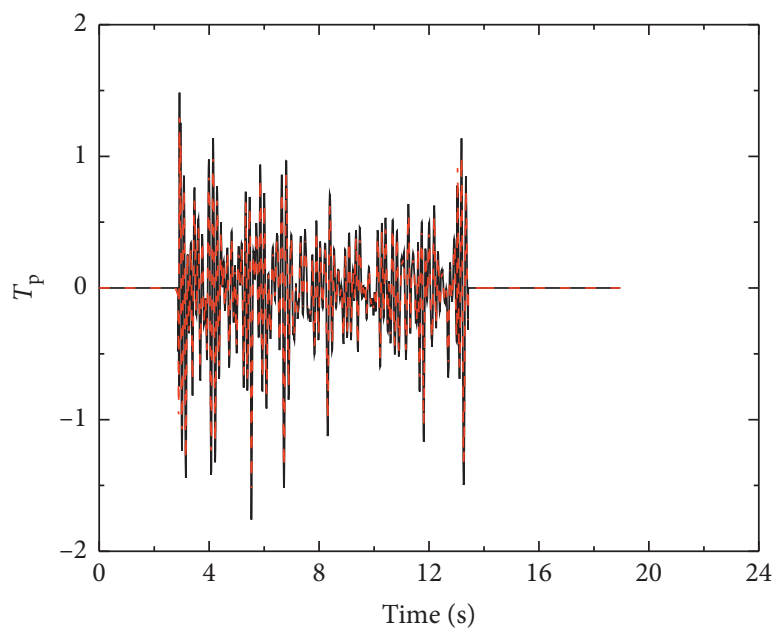

_ Before reinforcement

- - - After reinforcement

(e)

Figure 16: Continued. 


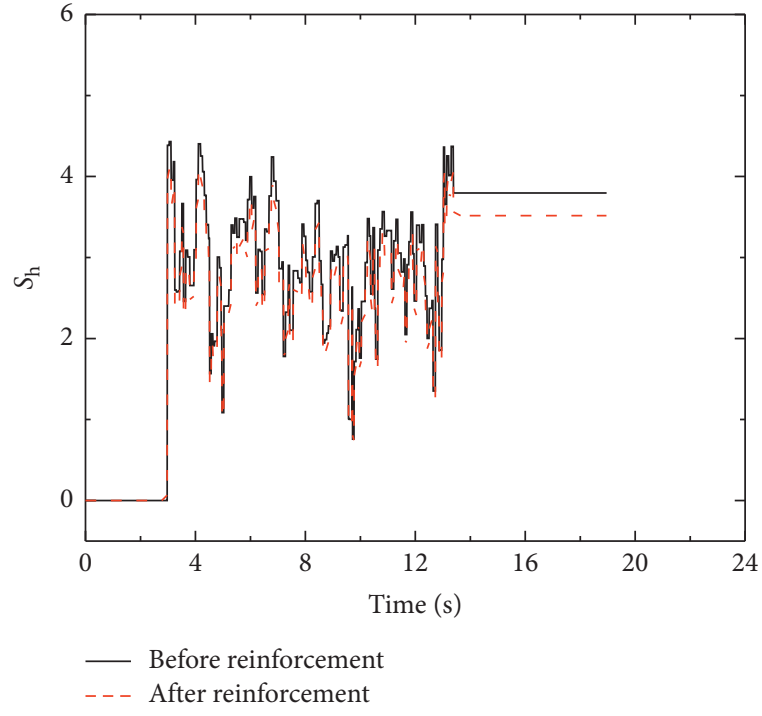

(g)

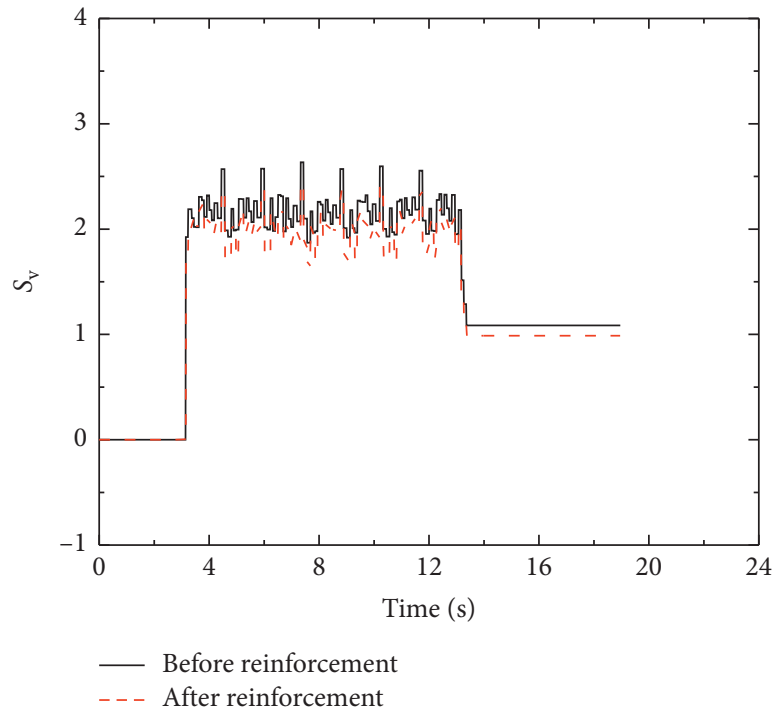

(h)

Figure 16: FTTB system spatial vibration response before and after the reinforcement under the action of empty wagon. (a) Time history curve of $B_{h}$, (b) time history curve of $B_{v}$, (c) time history curve of $C_{h}$, (d) time history curve of $C_{v}$, (e) time history curve of $D_{w}$, (f) time history curve of $T_{p}$, (g) time history curve of $S_{h}$, and (h) time history curve of $S_{v}$.

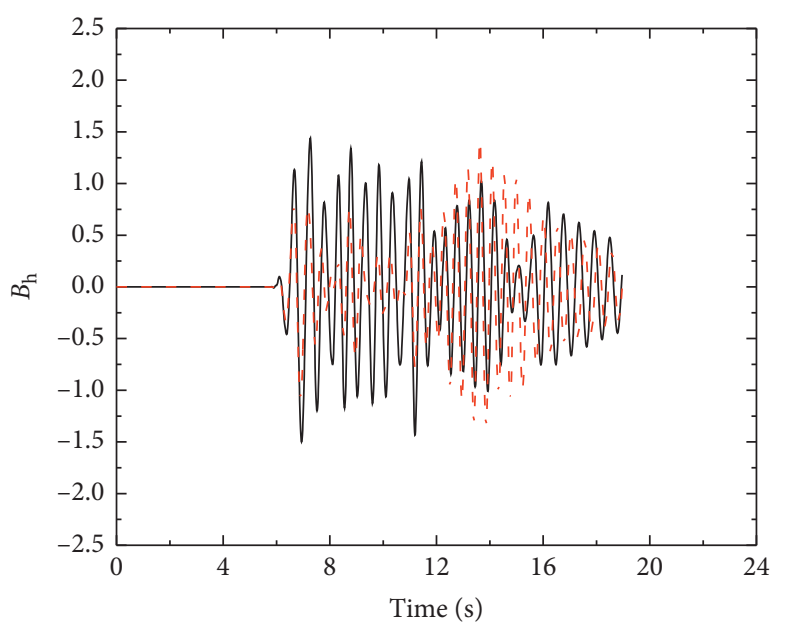

- Before reinforcement
--- After reinforcement

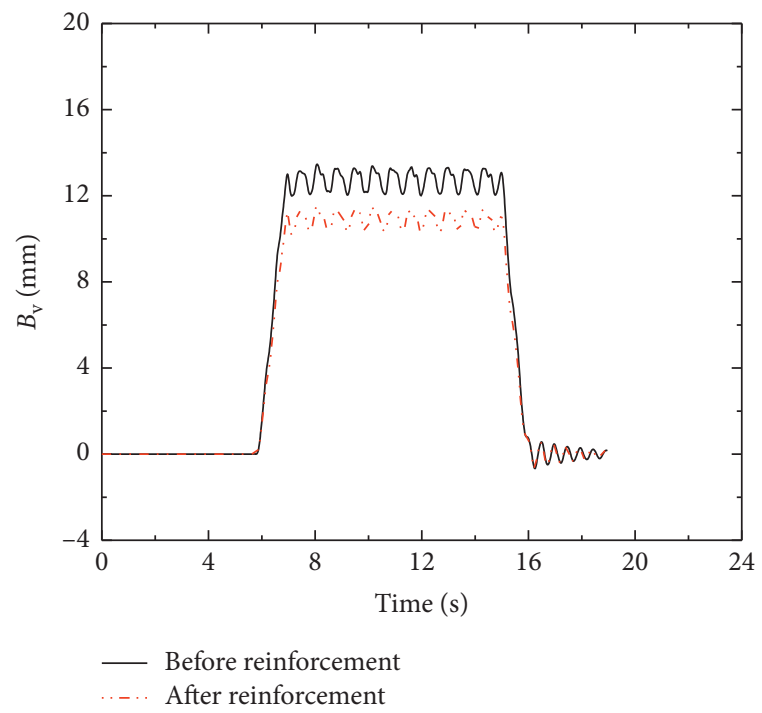

(b)

Figure 17: Continued. 


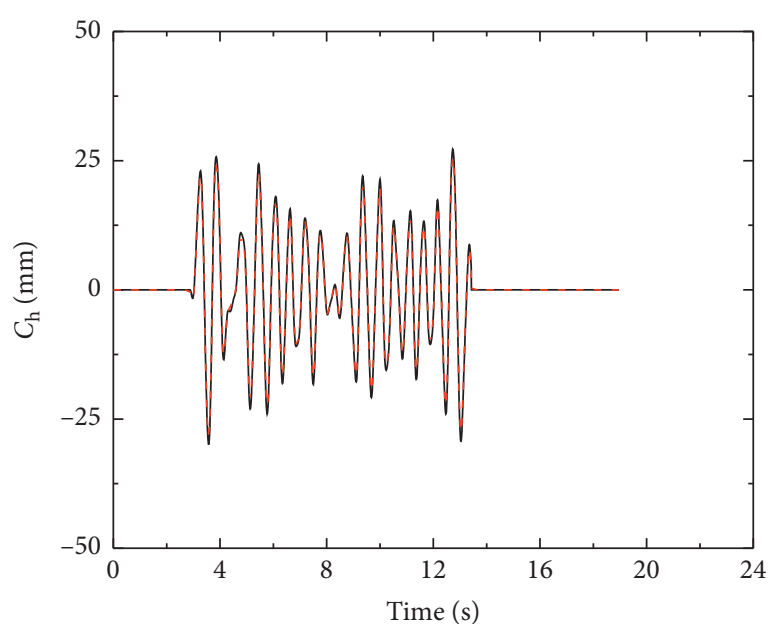

— Before reinforcement - - - After reinforcement

(c)

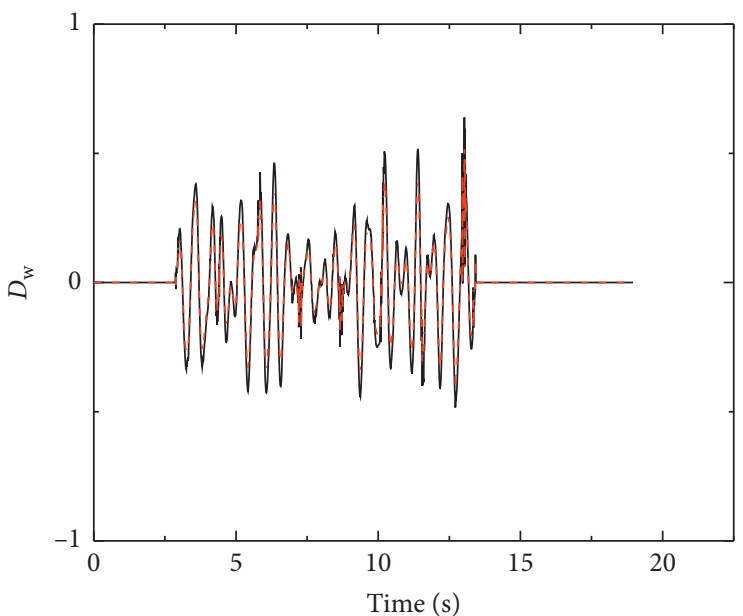

Before reinforcement After reinforcement

(e)

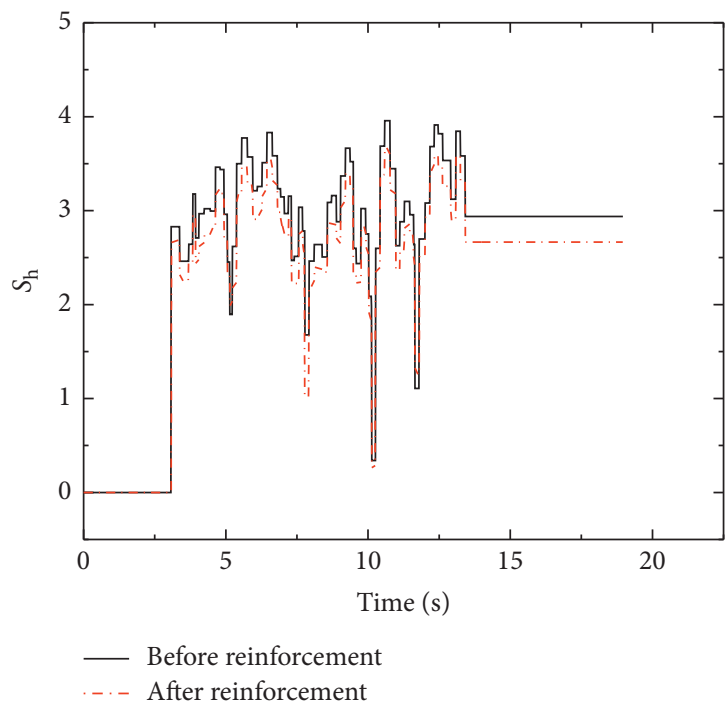

(g)

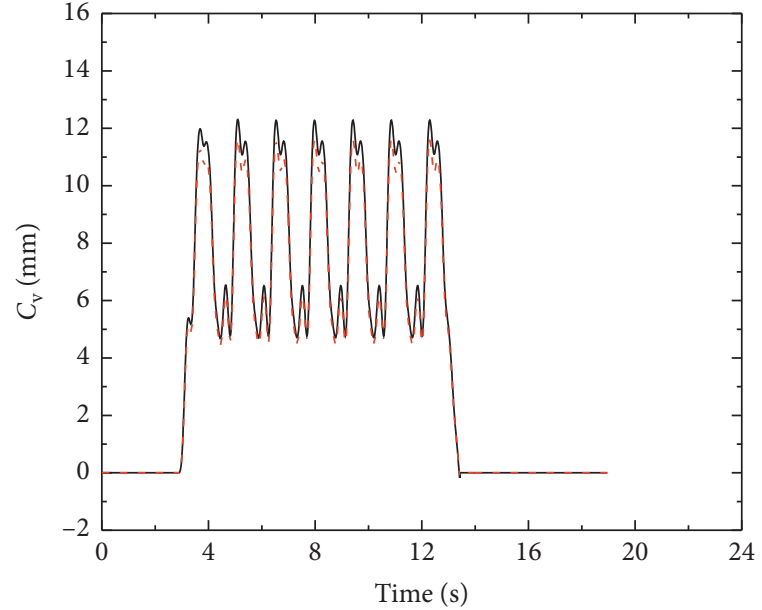

_ Before reinforcement

- - - After reinforcement

(d)

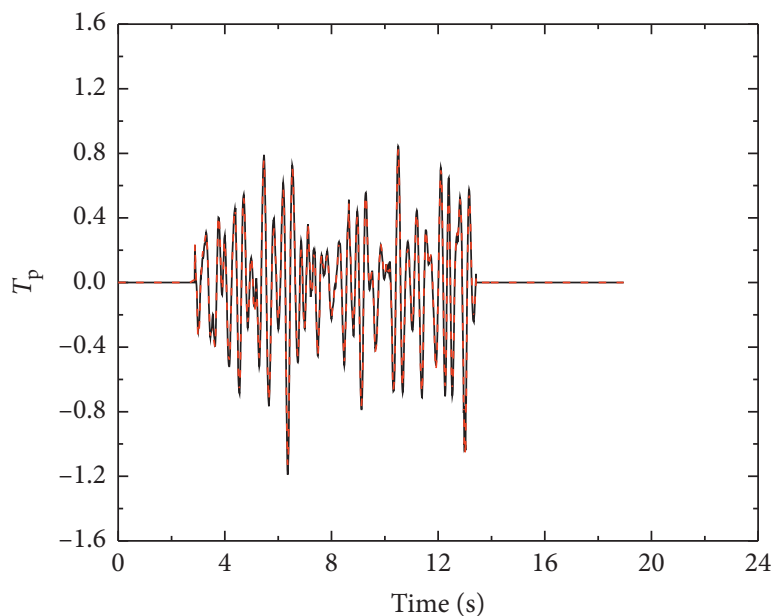

— Before reinforcement After reinforcement

(f)

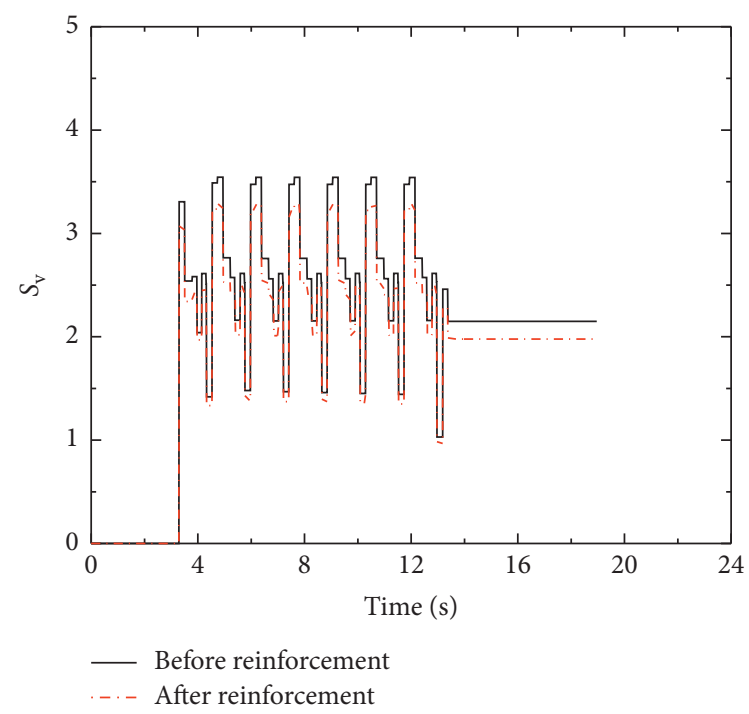

(h)

FIgURE 17: FTTB system spatial vibration response before and after the reinforcement under the action of a loaded train. (a) Time history curve of $B_{h}$. (b) Time history curve of $B_{v}$. (c) Time history curve of $C_{h}$. (d) Time history curve of $C_{v}$. (e) Time history curve of $D_{w}$. (f) Time history curve of $T_{p}$. (g) Time history curve of $S_{h}$. (h) Time history curve of $S_{v}$. 
In order to reflect the time history response changes of the abovementioned indexes before and after reinforcement, the time-history responses with $V=80 \mathrm{~km} / \mathrm{h}$ are listed as shown in Figures 16 and 17.

\section{Summary and Conclusions}

Based on the spatial vibration calculation model of FTTB system and the derailment energy random analysis method of train, the spatial vibration calculation model of FTTB system under the condition of auxiliary steel beam reinforcement is established, and then the evaluation method about running safety and dynamic response of auxiliary steel beam reinforcement is presented. The influence of antiderailment capacity, the critical speed, the allowable limit speed, and the spatial vibration response of FTTB system are analyzed. The following conclusions are obtained:

(1) Through comparative analysis, the calculated results of the model are basically consistent with the test results in the literature, which verifies the rationality of the model.

(2) The results show that the antiderailment capacity of FTTB system is improved by $22.6 \%$; before the reinforcement of auxiliary steel beam, the critical speed and allowable limit speed are $115.56 \mathrm{~km} / \mathrm{h}$ and $92.49 \mathrm{~km} / \mathrm{h}$, respectively, while after reinforcement, the critical speed and allowable limit speed are $132.73 \mathrm{~km} / \mathrm{h}$ and $106.18 \mathrm{~km} / \mathrm{h}$, respectively; the critical speed and allowable limit speed of auxiliary steel beam are increased by $14.8 \%$.

(3) Under the action of empty wagon, the mid-span transverse amplitude and vertical dynamic deflection of beam body, lateral displacement and vertical displacement of car body, wheel-load reduction rate, derailment coefficient, and lateral and vertical Sperling stability index increase with the increase of vehicle speed; after the auxiliary steel beam is reinforced, the maximum values of the above indexes are reduced by $12.1 \%, 5.9 \%, 13.3 \%, 4.8 \%, 8.2 \%, 8.3 \%$, $6.8 \%$, and $6.1 \%$, respectively. The lateral vibration response of FTTB system under the action of empty wagon is greatly affected by the reinforcement of auxiliary steel beam, which can meet the requirements of running stability at the speed of $90 \mathrm{~km} / \mathrm{h}$.

(4) Under the action of loaded wagon, the mid-span transverse amplitude and vertical dynamic deflection of beam body, lateral displacement and vertical displacement of car body, wheel load reduction rate, derailment coefficient, and lateral and vertical Sperling stability index increase with the increase of vehicle speed; after the auxiliary steel beam is reinforced, the above indexes decrease by $4.6 \%$, $10.6 \%, 4.8 \%, 3.9 \%, 18.6 \%, 4.3 \%, 6.5 \%$, and $6.7 \%$, respectively. When the speed is $90 \mathrm{~km} / \mathrm{h}$, the reinforcement of auxiliary steel beam has great influence on the vertical vibration response of FTTB system under the action of loaded wagon, which can meet the requirements of running stability at the speed of $90 \mathrm{~km} / \mathrm{h}$.

(5) The above method and results can provide reference for evaluation and formulation of reinforcement measures with derailment prevention function and meeting the requirements of driving stability.

\section{Data Availability}

All data generated or analyzed during this study are included in the published article.

\section{Conflicts of Interest}

The authors declare that they have no conflicts of interest regarding the publication of this paper.

\section{Acknowledgments}

This research was financially supported by the National Natural Science Foundation of China (51578238 and 52068028), Natural Science Foundation Committee of China and Shenhua Group Corporation Limited (U1261113), Jiangxi Province's Key Research and Development Plan (20181BBE50013), and Science and Technology of Jiangxi Provincial Education Department (GJJ170392).

\section{References}

[1] J. Xue, "Experimental study on strengthening method of bridges and culverts under $30 \mathrm{t}$ axle load in Shuo-Huang railway," Journal of The China Railway Society, vol. 37, no. 3, pp. 93-99, 2015.

[2] W. Zhai and H. Xia, Train-Track-Bridge Dynamic Interaction: theory and Engineering Application, Science Press, Beijing, China, 2011.

[3] C. Yin, "Research on comprehensive improvement and strengthening of small span bridge on heavy haul railway," Railway Standard Design, vol. 61, no. 4, pp. 83-87, 2017.

[4] A. M. Puurula, O. Enochsson, S. Gabriel et al., "Assessment of the strengthening of an RC railway bridge with CFRP utilizing a full-scale failure test and finite-element analysis," Journal of Structural Engineering, vol. 141, no. 1, pp. 1-11, 2015.

[5] AM. Robiul, T. Hayashikawa, X. He et al., "Improvement effects of bottom lateral bracing on dynamic performance of curved steel twin I-girder bridge under running vehicles," International Journal of Steel Structures, vol. 13, no. 2, pp. 275-290, 2013.

[6] A. Abu-Obeidah, R. A. Hawileh, and J. A. Abdalla, "Finite element analysis of strengthened RC beams in shear with aluminum plates," Computers \& Structures, vol. 147, pp. 36-46, 2015.

[7] K. C. Panda, S. K. Bhattacharyya, and S. V. Barai, "Strain analysis of RC T-beams strengthened in shear with variation of U-wrapped GFRP sheet and transverse steel," Advances in Structural Engineering, pp. 2001-2010, 2015.

[8] A. Bousselham and O. Chaallal, "Effect of transverse steel and shear span on the performance of RC beams strengthened in shear with CFRP," Composites Part B: Engineering, vol. 37, no. 1, pp. 37-46, 2006.

[9] C. Zhou and B. Liu, "Research on the mechanical properties of railway bridge strengthened with quick-composite 
reinforcement methods," Journal of Railway Engineering Society, vol. 5, no. 200, pp. 42-48+53, 2015.

[10] Y. Han, H. Xia, and N. Zhang, "Study on lateral rigidity reinforcement schemes for $32 \mathrm{~m}$ simply-supported PC Tbeams under train speed raising," Journal of the China Railway Society, vol. 27, no. 1, pp. 90-95, 2005.

[11] L. Jiang, W. Long, Z. Yu et al., "Dynamic response analysis of heavy-haul railway bridge strengthened by bonding assisted steel beams," Journal of Hunan University (Natural Sciences), vol. 40 , no. 7 , pp. $28-33,2013$.

[12] Q. Liu, The Research on Reinforcement Method of Heavy Haul Railway Bridge, Central South University, Changsha, China, 2013.

[13] F. Zhang, "Reinforcement test on super low-height girder by auxiliary steel beam method on Shuozhou-Huanghuagang railway," Railway Engineering, vol. 4, pp. 40-44, 2017.

[14] C. Cai, "Experimental study on reinforcing effect of ultra-low height prestressed concrete girder under heavy haul railway transport," Railway Engineering, vol. 6, pp. 7-10, 2016.

[15] K. Gong, J. Xiang, J. Mao, and C. Yu, "Derailment precautions of freight train on bridge in heavy haul railway," Journal of Central South University, vol. 48, no. 12, pp. 3406-3414, 2017.

[16] Q. Zeng, Xiangjun, Z. Zhou et al., Analysis Theory and Application of Train Derailment, Central South University Press, Changsha, China, 2006.

[17] Q. Zeng, P. Lou, and J. Xiang, “The principle of total potential energy with stationary value in elastic system dynamics and its application to the analysis of vibration and dynamic stability," Journal of Huangzhong University of Science \& Technology (Urban Science Edition), vol. 19, no. 1, pp. 7-14, 2002.

[18] Q. Zeng and P. Yang, "The "set-in-right-position" rule for forming structural matrices and the finite truss element method for space analysis of truss bridge," Journal of the China Railway Society, vol. 8, no. 2, pp. 48-59, 1986.

[19] C. Yang, Q. Li, W. Feng et al., "Static properties comparison of steel-concrete composite beams being equivalent as stiffness," Sichuan Building Science, vol. 38, no. 1, pp. 37-39, 2012.

[20] National Bureau of Standards, Railway Vehicle-Specification for Evaluation the Dynamic Performance and Accreditation Test, Standards Press of China, Beijing, China, 2019.

[21] L. Liang, X. Xiao, and X. Jin, "Study on derailment mechanism and safety operation area of high speed trains under earthquake," Journal of Computational and Nonlinear Dynamics, vol. 7, no. 4, pp. 152-165, 2012.

[22] Q. Zeng and X. Guo, Theory and Application of Train-Bridge Time-Variant System Vibration Analysis, China Railway Press, Beijing, China, 1999. 